\title{
PRIMER
}

\section{HIV infection}

\author{
Steven G. Deeks ${ }^{1}$, Julie Overbaugh ${ }^{2}$, Andrew Phillips ${ }^{3}$ and Susan Buchbinder ${ }^{1,4}$
}

Abstract | More than 75 million people worldwide have been infected with human immunodeficiency virus (HIV), and there are now approximately 37 million individuals living with the infection. Untreated HIV replication causes progressive $\mathrm{CD} 4^{+} \mathrm{T}$ cell loss and a wide range of immunological abnormalities, leading to an increased risk of infectious and oncological complications. HIV infection also contributes to cardiovascular disease, bone disease, renal and hepatic dysfunction and several other common morbidities. Antiretroviral drugs are highly effective at inhibiting HIV replication, and for individuals who can access and adhere to these drugs, combination antiretroviral therapy leads to durable (and probably lifelong) suppression of viral replication. Viral suppression enables immune recovery and the near elimination of the risk for developing acquired immune deficiency syndrome (AIDS). Despite effective treatment, HIV-infected individuals have a higher than expected risk of heart, bone, liver, kidney and neurological disease. When used optimally by an infected (or by an uninfected) person, antiretroviral drugs can virtually eliminate the risk of HIV transmission. Despite major advances in prevention sciences, HIV transmission remains common in many vulnerable populations, including men who have sex with men, injection drug users and sex workers. Owing to a lack of widespread HIV testing and the costs and toxicities associated with antiretroviral drugs, the majority of the infected population is not on effective antiretroviral therapy. To reverse the pandemic, improved prevention, treatment and implementation approaches are necessary.

Human immunodeficiency virus (HIV) infection probably spread from non-human primates to humans sporadically throughout the $1900 \mathrm{~s}^{1,2}$. However, only in the 1980s did the virus come to the world's attention, when homosexual men in urban centres began presenting with advanced and unexplained immunodeficiency ${ }^{3}$. Within 2 years of the first report of what eventually became known as acquired immune deficiency syndrome (AIDS), scientists discovered the causative virus: HIV $^{4,5}$. HIV has infected $>75$ million people worldwide, and an estimated 37 million people are now living with the virus ${ }^{6}$. HIV infection is one of the main causes of morbidity and mortality worldwide ${ }^{7}$, with most of the disease concentrated in sub-Saharan Africa. As the infection often takes hold in adults who are in the prime of their economic productivity, HIV infection has dramatically altered the economies of many countries. Its toll on human health - defined broadly - cannot be readily quantified.

On an individual level, the natural history of

Correspondence to S.G.D. e-mail:steven.deeks@ucsf.edu University of California, San Francisco, Department of Medicine, 995 Potrero Avenue, San Francisco, California 94110, USA system then achieves some degree of control, and a 'set point' is established in which the level of HIV replication remains relatively stable, often for years ${ }^{10}$. Through mechanisms that are probably multidimensional and still not fully defined, HIV causes progressive loss of $\mathrm{CD}^{+} \mathrm{T}$ cells and a host of immunological abnormalities $^{8,11}$. After several years, profound immunodeficiency emerges and individuals develop a characteristic infectious or oncological complication (these complications define AIDS; FIG. 1). Although the typical person progresses to death over a period of about 10 years, some progress rapidly, and a rare subset might never progress or progress very slowly ${ }^{12}$.

Antiretroviral therapy (ART) has been available to treat HIV infection for nearly two decades. When used appropriately, ART is highly effective - completely or nearly completely suppressing HIV replication, improving immune function and greatly reducing the risk of developing AIDS. However, ART is not curative; if drugs are stopped, the virus almost invariably rebounds within weeks ${ }^{13}$.

There are two main strains or types of HIV: HIV-1 and HIV-2 (BOX 1). In this Primer, we focus on HIV-1 as it is the more dominant and pathogenic stain. We first describe the epidemiology of HIV infection, highlighting the impact that ART has on a global level. We then discuss the pathogenesis of the infection, describing how HIV is transmitted, how it causes disease and how ART alters the virus-host interactions. We then discuss 


\section{Author addresses}

${ }^{1}$ University of California, San Francisco, Department of Medicine, 995 Potrero Avenue, San Francisco, California 94110, USA.

${ }^{2}$ Fred Hutchinson Cancer Research Center, Seattle, Washington, USA.

${ }^{3}$ Department of Infection and Population Health, University College London, London, UK.

${ }^{4}$ San Francisco Department of Health, San Francisco, California, USA.

current approaches in prevention and management. In our final section on the long-term outlook, we highlight some of the dynamic arenas of HIV research, including the development of effective vaccines and injectable formulations of ART, and emerging efforts to the cure the infection.

\section{Epidemiology}

\section{Key affected populations}

In nearly all regions of the world, HIV prevalence is highest in certain groups who share common risk factors. These key affected populations include men who have sex with men, intravenous drug users, people in prisons and other closed settings, sex workers and transgender people ${ }^{14}$. Each of these groups has complex legal and social issues related to their behaviours that increase their vulnerability to HIV infection, and prevent them from accessing prevention and treatment services. Given the high prevalence of HIV infection in these populations, they are considered as essential partners in an effective response to the pandemic. Infants of HIV-positive mothers are another group at high risk of infection, but one of the great success stories of HIV infection has been the near elimination of mother-to-child transmission when ART is used, as described below. On a global level, the incidence of HIV infection in the population of men who have sex with men has remained generally high over the past 10 years without evidence of decline observed in most communities in this time period ${ }^{15}$. This risk is due to, in part, the relatively high probability of transmission during receptive anal sexual intercourse and a higher number of exposures.

\section{Generalized epidemics and global epidemiology}

The HIV infection pandemic is generalized across the adult population in many regions of sub-Saharan Africa, with much of the burden of disease placed on women. In low-income and middle-income countries, approximately half of the people living with HIV infection are women; this proportion is higher (57\%) in sub-Saharan Africa ${ }^{16}$. Most of the transmission events occur as a result of heterosexual transmission from a partner whose HIV status was not known or disclosed (BOX 2). The Joint United Nations Programme on HIV/ AIDS (UNAIDS) regularly reports on the estimated burden of HIV infection in each country. On a per-capita basis, the countries with highest burden are Swaziland, Lesotho, Botswana and South Africa; South Africa is the country with the highest number of HIV-positive people $^{14}$. However, within many countries in this region, large differences in prevalence are evident by geographic region, with South Africa and Kenya being examples. For example, in South Africa, the prevalence of HIV infection (in people 15-49 years of age) in the Western Cape is $7.8 \%$, but $27.9 \%$ in KwaZulu-Natal ${ }^{17}$.

Although the burden has remained stable in many areas, it has declined in some countries, including Zimbabwe, Malawi and Tanzania ${ }^{14}$. This decline is probably owing to several factors, including increased use of condoms, which present a barrier to HIV transmission ${ }^{18}$; reductions in the prevalence of sexually transmitted infections, which are also associated with an increased risk of acquiring HIV infection; the saturation of the at-risk community; and, increasingly, the use of effective ART, which, as described below, makes an individual less infectious. Worldwide, 2 million new cases of people with HIV infections were estimated in 2014 - a decline of 35\% from 2000 (REF. 6).

\section{ART penetration}

In an unprecedented global response to the rapidly growing pandemic, several initiatives - including the President's Emergency Plan for AIDS Relief (PEPFAR; www.pepfar.gov) and the Global Fund for AIDS, Tuberculosis and Malaria (www.theglobalfund.org) - began over a decade ago to provide three-drug combination ART to poorly resourced countries, mostly in Africa. On a global level, approximately 15 million of the 37 million people infected with HIV are now on therapy $^{6},>10$ million of whom are in Africa ${ }^{6}$. As a consequence of antiretroviral drug rollout, AIDS-related mortality has declined globally from a peak level of 2.4 million deaths in 2005 to approximately 1.5 million deaths in 2013.

Owing to the provision of antiretroviral drugs, which prevents children from acquiring HIV infection from their mothers around the time of birth, progress in the prevention of new cases of HIV infection among children has been dramatic (BOX 3). In 2013, it was estimated that 240,000 children were newly infected with HIV, 58\% fewer than in 2002 (REF. 14). Since 2009, 900,000 new HIV infection cases have been prevented among children ${ }^{14}$.

\section{HIV care cascade}

Despite substantial public health investment in nearly all regions of the world, less than half of the HIV-infected population are receiving ART - this figure is somewhat higher in sub-Saharan Africa and lower in eastern Europe and central Asia as well as in north Africa and the Middle East ${ }^{6,14}$. Several barriers at various steps of the care pathway prevent full implementation of ART (FIG. 2), including limited availability and uptake of HIV testing, as no more than half of people with HIV infection have been diagnosed ${ }^{14}$. Among those known to be infected, linkage to and retention in care are incomplete ${ }^{19,20}$, and among those on ART, many have detectable viraemia. The lack of adherence programmes, routine viral load monitoring to detect treatment failure and affordable 

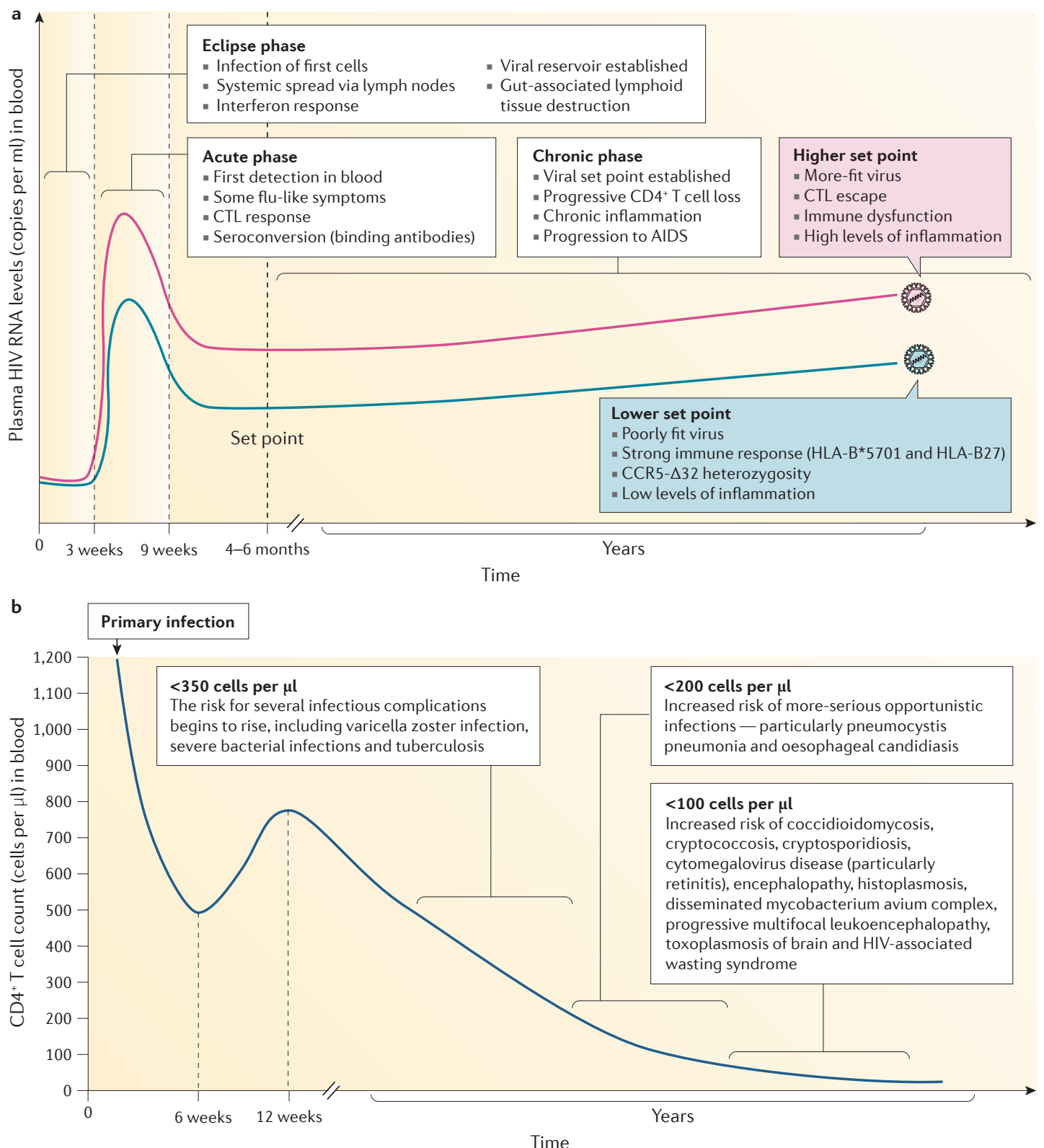

Figure 1 |HIV infection and AIDS. a|During prototypic HIV infection, the transmitted virus first infects target cells in mucosal tissues and then spreads through the lymphoid system (eclipse phase). HIV RNA levels first become detectable after several days and then increase exponentially, reaching a peak a few weeks later, at which point the adaptive immune response results in partial control. HIV antibody responses are largely ineffective owing to rapid viral escape. A steady-state level (set point) of viraemia, reflecting complex virus-host interactions, is then established. HIV-mediated destruction of $\mathrm{CD}^{+}{ }^{+} \mathrm{T}$ cells leads to immunodeficiency and chronic inflammation. $\mathbf{b} \mid$ The typical $C D 4^{+} T$ cell count in an adult is typically between 500 cells and 1,200 cells per $\mu$ l. As the $C D 4^{+} T$ cell number declines to $<350$ cells per $\mu$, the risk for several infectious complications begins to rise, leading to more-advanced disease (CD4 ${ }^{+}$T cell count $<100$ cells per $\mu l$ ). Indeed, HIV-associated immunodeficiency increases the risk of Kaposi sarcoma, certain lymphomas and invasive cervical cancer. The US Centers for Disease Control and Prevention defines AIDS on the basis of the presence of HIV infection and either a CD4 ${ }^{+} T$ cell count of $<200$ cells per $\mu$ or an AIDS-defining complication ${ }^{249}$. CCR5, CC-chemokine receptor 5; CTL, cytotoxic T lymphocyte; HLA, human leukocyte antigen.

second-line and third-line regimens means that many treated patients in low-income and middle-income countries might have incomplete viral suppression.

\section{Mechanisms/pathophysiology}

When the nature of the emerging epidemic became apparent in the mid-1980s, numerous government and industry partners began what became an unprecedented investment into understanding how HIV is transmitted and how it causes disease (FIG. 3). These investments eventually paid off in terms of the development of effective prevention and treatment strategies and have contributed to dramatic advances in the management of other infections, most notably hepatitis $B$ virus and hepatitis $C$ virus. 


\section{Box 1 | HIV-1, HIV-2 and SIV}

Human immunodeficiency virus (HIV) includes a diverse collection of viruses, including HIV type 1 (HIV-1) and HIV-2. HIV-1 is more prevalent and more pathogenic than HIV-2 and is responsible for the vast majority of the global pandemic. Sequence comparisons suggest that both HIV-1 and HIV-2 are the result of cross-species transmissions of simian immunodeficiency virus (SIV) from chimpanzees $\left(\mathrm{SIV}_{\mathrm{cpz}}\right.$ ) and sooty mangabeys $\left(S_{\mathrm{s} I \mathrm{~m}}\right)$, respectively. Interestingly, SIV infection in their natural hosts is less pathogenic than HIV-1 infection in humans. For example, SIV $_{\text {smm }}$ does not cause disease in sooty mangabeys but is highly pathogenic when transferred to rhesus macaques. The pathogenicity of HIV-2 in humans lies somewhere between that of SIV in sooty mangabeys and rhesus macaques. The reduced pathogenicity of HIV-2 in humans is thought to be the result of lower levels of virus replication, perhaps reflecting incomplete adaptation of SIV to the human host. HIV-2 infection is most prevalent in west Africa, although small epidemics have been reported in Portugal, France, Spain and Brazil. The incidence of HIV-2 infection is declining, potentially reflecting the low transmission rates associated with the low viral load. Specialized tests are needed to diagnose and monitor HIV-2 infection as standard HIV-1 assays have either given atypical results or failed to detect and quantify HIV-2 RNA; these tests are not widely available. Treatment is also complicated; non-nucleoside reverse transcriptase inhibitors, enfuvirtide (an entry inhibitor) and some protease inhibitors are not active against HIV-2 infection. Current guidelines suggest using standard monitoring to define when to start therapy ${ }^{170}$. Initial regimens should include two nucleoside analogues and either a boosted protease inhibitor with known activity against HIV-2 (for example, darunavir or lopinavir) or an integrase strand transfer inhibitor ${ }^{120,170}$.

\section{The virus}

Life cycle. HIV is a retrovirus and is, therefore, able to integrate its DNA into the host genome; this fact makes the virus exceedingly difficult to eradicate with current therapies. The virus has a small number of proteins and is remarkably efficient in its design. After gaining entry into a cell, single-strand RNA is reverse transcribed into HIV DNA, which is then integrated into the host DNA. Taking advantage of host enzymes, HIV is transcribed, proteins are produced and cleaved, and mature virions are released. These steps are now routinely inhibited in a therapeutic setting with a family of commercially available entry inhibitors, reverse transcriptase inhibitors, integrase strand transfer inhibitors and protease inhibitors (FIG. 4).

The primary receptor for HIV-1 is CD4, which is expressed on the surface of $\mathrm{T}$ lymphocytes, monocytes, macrophages and dendritic cells. HIV also requires a co-receptor to gain entry into the host cell, typically the chemokine receptors CCR5 and CXCR4. Different HIV-1 variants typically use one or the other chemokine receptor, but some can use either; viruses that use these co-receptors for entry are called R5, X4 or R5X4 viruses, respectively. CCR5 and CXCR4 are differentially expressed on some T cell subsets, with CCR5 expressed at high levels in memory $\mathrm{T}$ lymphocytes but not on naive T lymphocytes, whereas CXCR4 is expressed on both. CCR5 is also expressed on macrophages and dendritic cells.

The preferred targets for infection are activated $\mathrm{T}$ lymphocytes, which for reasons that remain to be defined are more permissive to infection than resting cells. Although dendritic cells are difficult to infect with HIV-1, they are able to 'capture' the virus and promote trans-infection of neighbouring $\mathrm{T}$ lymphocytes ${ }^{21}$. The virus can also attach to the follicular dendritic network, which retains the infectious virus in a concentrated manner within B cell follicles of lymph nodes. In addition, HIV causes lymphoid tissue fibrosis through several mechanisms, including upregulation of $\mathrm{T}$ regulatory cells and release of transforming growth factor- $\beta^{22,23}$. Tissue fibrosis persists during long-term effective ART ${ }^{24}$. Much of the harm associated with the virus in both untreated and treated disease probably occurs in these lymphoid structures ${ }^{25}$.

HIV evolution. One of the hallmarks of HIV-1 infection is the high rate of variation, estimated to be on the order of one mutation every few replication events ${ }^{26}$. This high error rate coupled with continual high-level virus replication leads to the extensive variation in HIV-1. Which of these variants survives and thrives is shaped by selective forces applied by the immune system and antiretroviral drugs $^{26}$. The envelope gene - which encodes the proteins that bind to CD4 and the co-receptors - is able to withstand extensive mutations, as shown by the fact that even within one infected individual the envelope sequence varies by $0.6-1 \%$ per year ${ }^{27,28}$. Envelope sequences from different individuals who are infected with different subtypes of HIV-1 differ on average by $25 \%$ and by as much as $35 \%{ }^{29}$. This diversity poses major challenges for the development of a preventive vaccine.

HIV transmission. As the initial events in HIV-1 infection are difficult to study in humans, much of our knowledge about this critical period comes from studies of the related simian immunodeficiency virus (SIV) infection in macaques. These studies show that productive infection of $\mathrm{CD} 4^{+} \mathrm{T}$ lymphocytes can be detected within the first 2 days of viral challenge ${ }^{30-32}$. The virus rapidly creates local foci of infection at the site of infection and then rapidly spreads to draining lymph nodes and eventually to distal lymph nodes and other tissues. In the SIV model, this all occurs within a 2-week period.

New infections are typically established by one or a few genetic variants ${ }^{33}$. Some variants can be more amenable to transmission (fitter) than others. Most notably, as CCR5 is highly expressed in $\mathrm{CD} 4^{+} \mathrm{T}$ cells within mucosal surfaces, the transmitted viruses almost invariably use CCR5 rather than CXCR4 for entry into the cell ${ }^{34-37}$. Indeed, individuals who lack CCR5 (who harbour the CCR5- $\triangle 32$ deletion) are almost fully protected from acquiring HIV infection ${ }^{38-41}$. During the course of HIV infection, the transmitted viruses evolve, presumably in response to changes in target cell population and immune response to the virus. In some but not all individuals, the virus population evolves from CCR5-tropic to CXCR4-tropic ${ }^{42}$; the mechanism for this shift remains poorly understood.

Studies have shown that the sequences of transmitted HIV-1 variants resemble the ancestral viral sequences from the infecting partner rather than the contemporaneous sequences, suggesting that the virus that was first acquired in the index case is still favoured for transmission compared with later-stage viruses ${ }^{43}$. Viruses that are transmitted tend to have envelope proteins with less glycosylation ${ }^{4-46}$ than those that are not transmitted, 
and some evidence suggests that transmitted viruses are less sensitive to the antiviral activities of interferons than those that are not transmitted ${ }^{47,48}$. The less-sensitive nature of transmitted viruses to interferons is of relevance given that HIV-1 induces a rapid interferon response - the virus must be able to circumvent this response to successfully establish a persistent infection ${ }^{49,50}$.

Primary or acute infection. The detection of virus in the blood (typically measured as viral RNA levels) is often associated with a short symptomatic phase marked by fever, generalized lymphadenopathy, a nonspecific rash, myalgias and/or malaise. More-severe complications including meningitis - can occur, but many people are asymptomatic. During this period of primary or acute infection, the plasma levels of HIV RNA are typically at their peak (approximately $10^{6}-10^{7}$ copies per $\mathrm{ml}$ ). The severity of symptoms is strongly correlated with peak viral load during this phase of the infection ${ }^{51}$. Once the immune response develops (see below) ${ }^{52}$, the levels of virus decrease by about 100 -fold to a steady-state level that is often referred to as the viral set point (FIG. 1a). This level can range from very few copies per $\mathrm{ml}$ of blood to approximately $10^{6}$ copies per $\mathrm{ml}$ and tends to be higher in infants than adults ${ }^{53,54}$. Importantly, the set point level is correlated with clinical outcome: individuals with high viral load set point typically progress more rapidly to AIDS and death than those with lower viral set point levels ${ }^{10}$. Those very few individuals with very low viral load set points are referred to as HIV elite controllers and are of high interest (BOX 4).

Features of both the virus and the host contribute to determination of the set point and the subsequent disease progression. In the SIV macaque model, different genetic variants have been shown to have distinct replication properties that influence clinical outcomes ${ }^{55}$. In the case of HIV infection, population-based studies also support

\section{Box 2 | HIV infection in women}

Among individuals 15-49 years of age living in South Africa in 2012, HIV incidence was estimated to be almost twofold higher in women than in men $^{17}$. Indeed, adolescent girls and young women (15-24 years of age) are particularly at risk for acquiring HIV infection. Violence against women, and lack of access to care and education are key factors that contribute to this epidemic ${ }^{14,219}$. The burden of HIV infection among women has also increased in high-income regions. According to the US Centers for Disease Control and Prevention, women accounted for $20 \%$ of the new cases of infection in the United States in 2010, most through heterosexual contact. Approximately $25 \%$ of those living with HIV infection in 2011 in the United States were women ${ }^{220}$. For reasons that remain largely undefined, women have a lower viral load set point than men (by approximately $0.2-0.4 \log _{10}$ copies of RNA per $\mathrm{ml}$ in most studies) yet progress at about the same rate ${ }^{221}$. HIV-associated inflammation might be higher in women than in men ${ }^{222}$, and the influence of HIV infection on risk of certain co-morbidities (particularly cardiovascular disease) might be greater ${ }^{223}$. In general, the virological and immunological response rates to combination antiretroviral therapy are comparable in men and women ${ }^{224,225}$, although adverse effects and drug toxicities seem to be more common in women than in men $^{226}$. As women have been historically under-represented in clinical research studies, several important issues remain undefined, including the effect that hormonal contraception and menopause have on HIV infection, sex-based differences in pharmacology on tolerability and safety of antiretroviral drugs, differential rates of adherence to and efficacy of pre-exposure prophylaxis and the effect of HIV infection on sexual well-being, stigma and quality of life ${ }^{120,142}$. a role for viral genotype in clinical outcome. Studies of transmission within couples, and in transmitting mothers and their infected infants, have shown that set point viral load levels are correlated in transmission pairs ${ }^{56,57}$, suggesting that viral characteristics determine replication and pathogenesis. Two recent studies have also shown that approximately one-third to one-half of variation in set point viral load is attributable to viral genotype ${ }^{58,59}$.

HIV reservoir. Through mechanisms as yet poorly understood, HIV establishes quiescent (or latent) infection within memory $\mathrm{CD} 4^{+} \mathrm{T}$ cells. These cells are maintained indefinitely through homeostatic proliferation; some cells have stem-cell-like capacity for self-renewal ${ }^{60,61}$. HIV can also establish long-term infection of naive $\mathrm{CD} 4^{+} \mathrm{T}$ cells, cells of the monocyte and macrophage lineage, and perhaps other long-lived cells ${ }^{62-65}$. As demonstrated in the SIV macaque model, this reservoir of infected cells can be established as early as 3 days after infection ${ }^{66}$. Once HIV DNA is integrated into the host chromatin, the virus has the capacity to reinitiate rounds of replication as long as the cell persists ${ }^{62,63,65}$. ART can prevent new cells from becoming infected, but these drugs cannot eliminate infection once the viral DNA is successfully integrated into its target cell. Owing to the inherent potency of ART, replication is nearly completely inhibited, but residual replication at very low levels seems to occur in at least a subset of patients $s^{67,68}$. The lymph nodes that harbour the virus can be a 'sanctuary' for the virus in terms of limited antiretroviral drug penetration ${ }^{69}$ and limited host clearance mechanisms ${ }^{70}$. This reservoir is also the source of virus recrudescence among effectively treated individuals who interrupt or stop ART.

Current estimates suggest it would take several decades for the reservoir to decay to negligible levels naturally, assuming all new infection events are inhibited with $\mathrm{ART}^{71}$. Accelerating the rate of this decay could conceivably lead to a cure (see Outlook, below).

\section{The host response}

Adaptive immunity. Much of our knowledge of the immune mechanisms for HIV control in vivo is derived from careful study of HIV elite controllers, who maintain undetectable or very low levels of virus in the absence therapy (BOX 4). Human leukocyte antigen$\mathrm{B}^{\star} 5701$ (HLA-B ${ }^{\star 5701)}$ in particular, but also other HLA alleles, are associated with control of HIV infection in the absence of therapy ${ }^{72,73}$. Of note, HLA has emerged as the most significant host genetic variant of viral control in subsequent genome-wide association studies, with limited evidence for other host singlenucleotide polymorphisms having a significant role ${ }^{72,73}$. Overall, these host genetic differences are thought to contribute approximately $10-15 \%$ of the variation in clinical outcome $e^{58,72}$.

The approximate 100-fold decrease in viral load as acute infection resolves is assumed to be attributable in large part to the development of HIV-specific CD8 ${ }^{+}$cytotoxic T lymphocytes (CTLs). With few exceptions (BOX 4), this response fails to durably control the virus. With chronic exposure, the cells become dysfunctional ${ }^{74,75}$. 
In addition, as with antibody responses, the virus rapidly generates CTL escape mutations, leading to a loss of virus control and the establishment of a lifelong reservoir of viral strains that are impervious to the host primary clearance mechanisms $s^{52,76}$. Other cellular responses such as antibody-dependent cell-mediated cytotoxicity have also been associated with viral control in multiple studies $^{77}$, although the contribution of antibody-dependent cell-mediated cytotoxicity in HIV infection is less well studied than that of the CTL response.

Immune evasion. The pathways that lead to immune clearance escape in vivo are not confined to those mutations that simply prevent direct recognition of the epitope. Envelope has considerable flexibility in the length of the variable loops and the extent of glycosylation, and longer loops and increased glycosylation can help to shield key epitopes $^{78,79}$. Similarly, several binding surfaces of envelope, including the CCR5 co-receptor-binding domain, are only transiently exposed during the entry process, effectively masking conserved functional domains that could be targets for antibodies ${ }^{79}$. In addition, mutations outside of the antibody epitope might disrupt the epitope by causing conformational changes ${ }^{79}$.

Once the virus evades antibodies and enters the cell, it must evade cellular restriction factors, such as the apolipoprotein B mRNA-editing catalytic polypeptide-like 3 (APOBEC3) proteins (which mutate viral genomes), SAM and HD domain-containing protein 1 (SAMHD1; which depletes the pool of nucleoside triphosphates that are needed for reverse transcription) and tetherin (which prevents budding viruses from leaving). The viral accessory proteins Vif, Vpx and Vpu are responsible for neutralizing the activity of APOBEC3G, SAMHD1 and tetherin, respectively ${ }^{80-82}$. The HIV accessory protein Nef causes downregulation of HLA class I molecules in infected cells, which results in suboptimal presentation of HIV peptides to cytotoxic T cells ${ }^{83}$.

\section{Box $3 \mid$ HIV infection in children}

An estimated 2.6 million children $<15$ years of age are living with HIV infection, most $(90 \%)$ of whom are in sub-Saharan Africa. The vast majority of children are infected in utero or during delivery and breastfeeding. Maternal HIV antibodies persist for up to 18-24 months in infants, making the diagnosis of HIV infection challenging. Viral load tests are necessary to make the diagnosis, but these tests are expensive, slow and require access to specialized laboratories ${ }^{227}$. Untreated HIV infection in an infant is associated with a high mortality rate ${ }^{228}$. In a randomized study in infants $<12$ weeks of age, immediate therapy was associated with a $75 \%$ reduction in mortality compared with delayed treatment ${ }^{229}$. Accordingly, immediate therapy is recommended for infected infants $<12$ months of age ${ }^{120,227}$. For older children, rates of disease progression tend to be slower ${ }^{230}$. The US Department of Health and Human Services guidelines suggest that antiretroviral therapy (ART) initiation be considered for all children, but only urgently initiated if children are $<12$ months of age or have high viral loads, clinical symptoms and immune suppression ${ }^{227}$. The WHO guidelines recommend ART for all children, noting that it is most urgent for those aged $<12$ months or who have low $C D 4^{+} T$ cell counts. Despite these guidelines, the data available for guiding clinicians on the optimal dose and formulation in children are scant ${ }^{227}$. Protease inhibitors or non-nucleoside reversetranscriptase inhibitors are currently recommended as first-line regimens, each given in combination with two nucleoside analogues ${ }^{227}$. In addition, there are concerns that HIV infection and/or its treatment have cumulative effects on cardiovascular, nervous, bone and other tissues, resulting in excess morbidity in adulthood ${ }^{231}$.
HIV 'superinfection'. Interestingly, individuals infected with HIV from one source partner remain at risk for a second infection from another source partner ${ }^{84}$. Although the incidence of second infection is somewhat lower than that of first infection ${ }^{85}$, this occurrence nonetheless implies that the immune response to one strain of HIV is at best only partially protective against another strain. Thus, HIV-specific immune responses induced by vaccination will most likely need to be more broad and potent than those typically elicited by natural infection, in which there is also immune system compromise.

$\mathrm{CD4}^{+} \mathrm{T}$ cell decline. During primary infection, a transient reduction in peripheral $\mathrm{CD} 4^{+} \mathrm{T}$ lymphocyte counts can often be detected, but these cell counts typically rebound to near-normal levels after primary infection resolves and then slowly decline over many years (FIG. 1 b). Over time, the virus causes a slow depletion of circulating and tissuebased $\mathrm{CD} 4^{+} \mathrm{T}$ cells. Much of the HIV replication and presumably $\mathrm{CD}^{+}{ }^{+} \mathrm{T}$ cell death occurs in gut-associated lymphoid tissue, which harbours high numbers of susceptible memory T lymphocytes. The high levels of replication in gut-associated lymphoid tissue in primary infection causes severe $\mathrm{T}$ cell depletion that is thought to make the intestinal lining permeable; systemic translocation of bacterial products leads to increased immune activation $^{86}$. HIV infection causes dramatic and sustained increases in the frequency of activated and proliferating $\mathrm{CD}^{+}$and $\mathrm{CD}^{+}{ }^{+} \mathrm{T}$ cells, many of which are destined to die even in the absence of infection. This generalized activation of the immune system contributes to the progressive loss of these cells, and the degree to which HIV infection causes $T$ cell activation is an independent predictor of the rate at which individuals lose $\mathrm{CD} 4^{+} \mathrm{T}$ cells and progress to $\operatorname{AIDS}^{87,88}$.

Several mechanisms probably account for how HIV depletes $\mathrm{CD}^{+}{ }^{+} \mathrm{T}$ cells. HIV replication can be directly cytopathogenic, although this is unlikely to account for all cell death, particularly in chronic infection. HIV infection of lymphocytes can generate incomplete reverse transcripts (HIV DNA), which stimulates an intense inflammatory response and death of local uninfected cells $^{89}$. In addition to causing cell death directly or indirectly, HIV negatively affects the capacity of the immune system to regenerate new $\mathrm{CD} 4^{+} \mathrm{T}$ cells, in part by causing harm to stem cells and the thymus ${ }^{11}$ (FIG. 5).

\section{Diagnosis, screening and prevention}

\section{Risk factors for HIV acquisition}

HIV is transmitted through contact of infected body fluids with mucosal tissue, blood or broken skin (TABLE 1). Factors that increase the infectiousness of a person infected with HIV include higher levels of virus in plasma ${ }^{90}$ or genital secretions $s^{91}$, and other sexually transmitted infections ${ }^{92}$ Virus characteristics, such as higher envelope content, increased cell-free infectivity, increased interaction with dendritic cells and resistance to IFNa have been associated with increased infectivity ${ }^{48}$. HIV-negative people can be more susceptible to infection if they have a larger number of potential target cells (that is, activated CD $4^{+}$ $\mathrm{T}$ cells) at the site of exposure, which would occur if they 


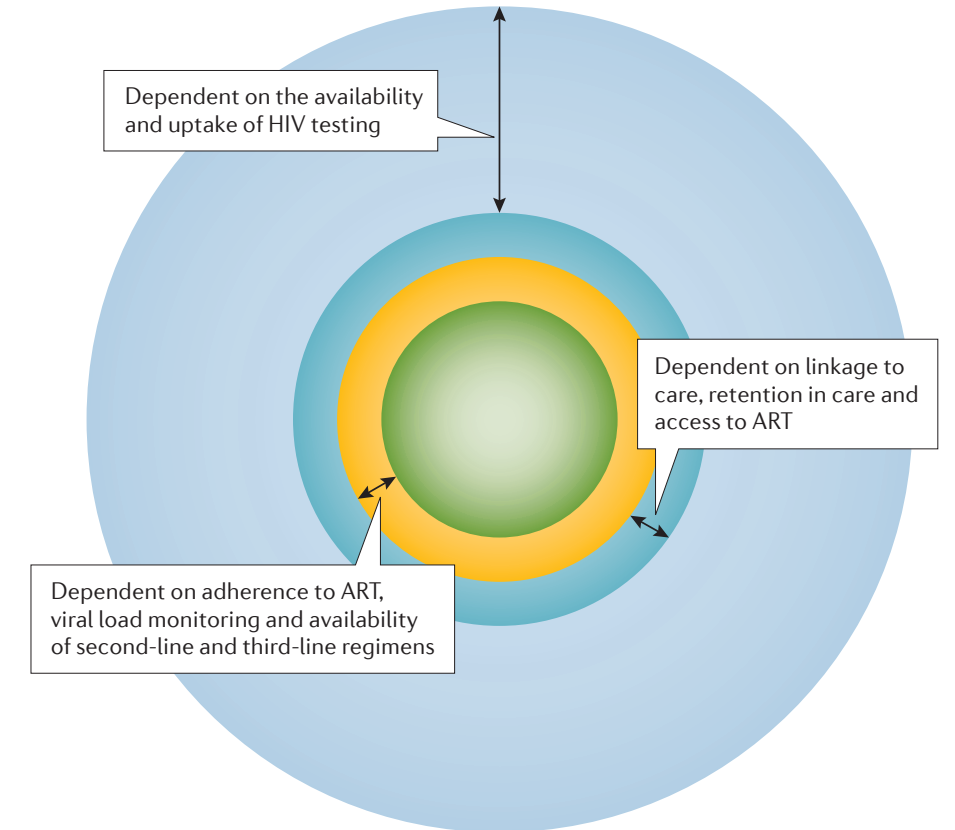

1 People living with HIV infection

- People who have been diagnosed

Figure 2 | HIV care cascade. Although antiretroviral therapy (ART) is very effective and generally safe, the majority of the population in nearly all of the regions and communities studied to date are not on fully effective therapy. There are multiple points in the delivery of care that contribute to the limited penetration of ART globally.

were infected with other sexually transmitted infectious agents or after trauma ${ }^{9}$. This notion extends to the association of male circumcision with lower HIV acquisition risk $^{93}$; several mechanisms have been proposed for the role of the foreskin in HIV acquisition, including having a large surface area that is rich in activated target cells, having slow-healing micro-abrasions from sexual activity in uncircumcised men and acquiring protective changes in the penile microbiota after circumcision ${ }^{94-96}$. Long-acting injectable hormonal contraception has also been linked to increased HIV acquisition in observational studies $^{97}$, possibly as a result of thinning of the vaginal epithelium, increased number of activated $\mathrm{CD} 4^{+} \mathrm{T}$ cells and/ or reduced condom use in these women. Intravenous and non-intravenous drug use also increase the risk of HIV acquisition; the former through direct parenteral exposure and the latter probably owing to behavioural factors, such as sex without condom use, or selection of partners who are more likely to be infected with HIV.

Social and structural factors also drive HIV susceptibility and might account for some of the disparities observed in HIV prevalence and incidence within various populations. For example, smaller sexual networks might enable more-rapid dissemination of HIV than larger networks, as relatively small increases in the number of partners create substantial increases in connectivity within the network, before reaching saturation ${ }^{98}$. Furthermore, HIV is more likely to spread through sexual networks with larger numbers of undiagnosed and/or undertreated HIV-positive sexual partners.

\section{HIV diagnosis}

HIV testing algorithms generally have changed over time, as test accuracy has increased. Current US Centers for Disease Control and Prevention ${ }^{99}$ and European guidelines for HIV testing ${ }^{100}$ recommend that screening be performed with an antigen-antibody assay (these assays are considered to be fourth generation; TABLE 2). Positive results should be confirmed with an antibody assay that can differentiate between HIV-1 and HIV-2 infections.

Detection of acute infection is important to prevent onward HIV transmission. Acute infection is thought to contribute disproportionately to new infections ${ }^{101,102}$ : reasons include higher viral levels during this period, higher infectiousness of the recently transmitted virus ${ }^{103}$ and continued behavioural risk-taking by individuals unaware of their recently acquired HIV infection ${ }^{104}$. Immediate initiation of ART will reduce the symptoms of acute HIV infection, potentially reduce seeding of viral reservoirs and maintain the health of the newly infected individual while reducing the risk of transmission to uninfected partners (see below).

Rapid HIV testing, using blood from a finger-stick or collection of oral fluid, can provide HIV-1 infection test results within 30 minutes, and is useful in settings in which follow-up care of patients is challenging, such as for public outreach-based testing at bars or street fairs. However, most currently licensed rapid tests have limited sensitivity for detecting acute HIV infection; if possible, more-sensitive fourth-generation antigen-antibody tests and/or nucleic acid tests should be included when risk factors are suggestive of acute infection. The reduced sensitivity of testing in oral fluid secretions adds approximately 6 weeks to detection of the same test performed in blood specimens ${ }^{105}$. HIV immunoassays can revert to non-reactive after long-term suppressive therapy in some people infected with HIV ${ }^{106}$; thus, HIV testing should not be conducted in treated people who are already confirmed to be HIV positive.

The US Preventive Services Task Force recommends HIV testing at least once for all people 15-65 years of age, with more frequent testing for individuals at increased risk $^{107}$. Individuals who are considered to be at high risk include sexually active men who have sex with men (except those in mutually monogamous relationships with an HIV-negative partner), active injection drug users and those who have acquired or seek testing for sexually transmitted infections. Other behavioural risk factors include anal or vaginal sex without condom use, particularly in those whose partners are at risk for HIV infection, and the exchange of sex for drugs or money. Recommendations for testing frequency for people at high risk generally suggest testing every 3-6 months, with concomitant testing for bacterial sexually transmitted infections. WHO guidelines recommend that in generalized HIV epidemics, all children and adults presenting for medical care should receive recommendations for HIV testing and have testing provided ${ }^{108}$. Such efforts should be supplemented by community-based and home-based HIV testing, to reach those who are not coming into care. 


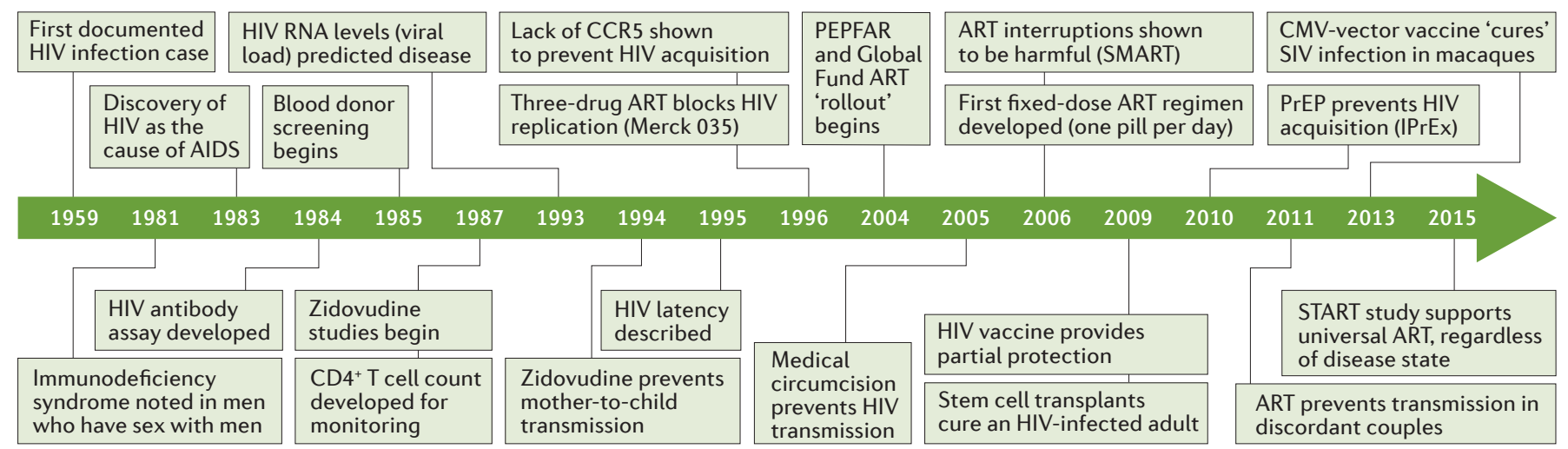

Figure 3 | Key milestones in history of HIV research and care. The pace of discovery in the HIV infection arena has been impressive, owing in large part to the major investments by the NIH and other funding agencies and industry. It took only a few years to go from the discovery of HIV infection ${ }^{4,5}$ to the accelerated approval of the first antiretroviral drug zidovudine and eventually to the development and approval of a fully effective three-drug regimen ${ }^{250}$. The same level of development cannot be said of prevention, but the past few years have witnessed progress in using antiretroviral therapy (ART) to prevent the sexual transmission of HIV infection. CCR5, CC-chemokine receptor 5; CMV, cytomegalovirus; IPrEx, Iniciativa Profilaxis Pre-Exposición study; PEPFAR, US President's Emergency Plan for AIDS Relief; PrEP, pre-exposure prophylaxis; SIV, simian immunodeficiency virus; SMART, Strategies for Management of Antiretroviral Therapy; START, Strategic Timing of AntiRetroviral Treatment.

Although pre-test and post-test risk reduction counselling has been recommended for many years, strategies to increase the uptake of HIV testing in the United States have emerged and include dropping requirements for written informed consent and prevention counselling with HIV testing ${ }^{109}$. Opt-out testing is now recommended in many medical settings ${ }^{109}$. Data indicate that these measures have increased the uptake of HIV testing in hospitals ${ }^{110}$, emergency departments ${ }^{111}$ and with young people in multiple locations in the United States ${ }^{112}$.

\section{HIV prevention}

Condom use in men has been a cornerstone of HIV prevention, as perfect use should completely prevent HIV transmission, as well as transmission of many other sexually transmitted infections. However, condom effectiveness has been estimated to be approximately $80 \%$ against heterosexual transmission of HIV infection ${ }^{113}$ and $70 \%$ against male-to-male sexual transmission ${ }^{114}$. Over-reporting of condom use probably contributes to these lower than expected effectiveness estimates, although improper use and condom failure also play a part $^{115}$. Similarly, providing clean injection equipment can substantially reduce HIV transmission in injection drug users ${ }^{116}$, although syringe exchange programmes have not eliminated HIV transmission in drug users. Additional prevention tools are needed to augment these core strategies.

Prevention of mother-to-child transmission. In the absence of ART, HIV transmission rates from mother to newborn are common (15-25\%) and are almost doubled by breastfeeding (approximately 35-40\%) ${ }^{117}$. HIV transmission can occur during pregnancy, labour and delivery, or through breastfeeding. However, ART can be used to reduce infectiousness in the mother by reducing her viral load and as prophylaxis for the infant to prevent the incoming virus from establishing infection. Indeed, ART given to pregnant women with HIV infection and continued through the breastfeeding period reduces HIV transmission rates to $<5 \%{ }^{118}$. Elective caesarean delivery can be used when women have been diagnosed too late to achieve full viral suppression. Infant infection rates of $1-2 \%$ have been reported in low-income countries ${ }^{119}$. The WHO recommends that all HIV-positive pregnant and breastfeeding women be treated with antiretroviral regimens that maintain viral suppression, and that these regimens be maintained at least for the duration of the transmission risk ${ }^{120}$. It is also recommended that infants receive short-term ART for prophylaxis after birth. In addition, the WHO recommends that treatment be continued throughout the lifetime of the HIV-positive woman, as ART provides health benefits, reduces sexual transmission and prevents mother-to-child transmission during future pregnancies.

Medical circumcision. Three large randomized controlled trials of medical circumcision of HIV-negative men in sub-Saharan Africa demonstrated a reduction in HIV acquisition of 50-60\% compared with uncircumcised men ${ }^{121-123}$, with increased protection observed over almost 5 years of follow-up ${ }^{124}$. Circumcision for HIVpositive men did not seem to reduce HIV transmission to their female partners, and the risk of transmission was increased when men resumed sexual activity before full healing of the circumcision wound ${ }^{125}$. Circumcision has also been shown to reduce the risk of other sexually transmitted infections ${ }^{123,126}$. A modelling consortium concluded that, over a 10-year period, one HIV infection could be averted for every $5-15$ circumcisions performed in generalized epidemics ${ }^{127}$. The WHO recommends that male circumcision be considered an important component of comprehensive HIV prevention; this policy has been endorsed by ministers of health, policy makers 
and global stakeholders. However, there are insufficient data available about the potential role of circumcision in preventing HIV acquisition in circumcised men who perform anal sex with men (insertive anal sex) ${ }^{128}$.

Treatment as prevention. Observational studies have suggested that people with lower levels of viraemia are less likely to transmit HIV infection than those with high viral loads $s^{90}$. A randomized controlled trial of early (initiating ART at a CD4 $4^{+} \mathrm{T}$ cell count of $>350$ cells per $\mu$ l) versus usual ART (initiated according to local guidelines) in serodiscordant couples (in which only one of the partners is HIV positive) demonstrated a $96 \%$ reduction in HIV transmissions from the HIV-positive partner in the treated group ${ }^{129}$. All infections except one in the early ART group resulted from partnerships outside of the primary (study) relationship, as determined by genetic sequencing of the infecting virus. Although only $2 \%$ of the couples in this study were men who have sex with men, preliminary results from two other studies also suggest that ART reduces transmission in men who have sex with men when HIV replication was fully controlled, as defined by an undetectable viral load ${ }^{130,131}$. Several other studies suggest that there may be a residual risk of HIV transmission in the several months after initiating ART; new infections did not occur after 6 months of treatment ${ }^{132}$. However, as a note of caution, another study among 14,000 HIV-infected clinic patients in six US cities, $>90 \%$ of whom were receiving ART, plasma viral load was at a level commensurate with the risk of transmission ( $>1,500$ RNA copies per $\mathrm{ml}$ ) for $>23 \%$ of the follow-up period ${ }^{133}$. Thus, it is important to remind patients who are being treated for HIV infection that the benefit of reduced risk of transmission comes from persistent viral load suppression. HIV-negative patients should be made aware that they may become infected from an HIV-positive partner if the partner is incompletely treated or recently non-adherent. Several large studies assessing the effect of ART on transmission at the community level are ongoing (see Outlook, below).

Post-exposure prophylaxis. Beginning in the 1990s, animal studies demonstrated that antiretroviral drugs, when given before or shortly after SIV challenge, could reduce or eliminate the risk of infection ${ }^{134}$. The data indicated that post-exposure prophylaxis should begin as soon as possible after exposure, but no longer than 72 hours after exposure, and treatment should continue for 4 weeks to maximize the chance that productive infection is prevented. Although these parameters have not been confirmed in controlled clinical trials ${ }^{135}$, these general guidelines have been followed for both occupational and non-occupational (sex or drug userelated) exposures in many industrialized countries.

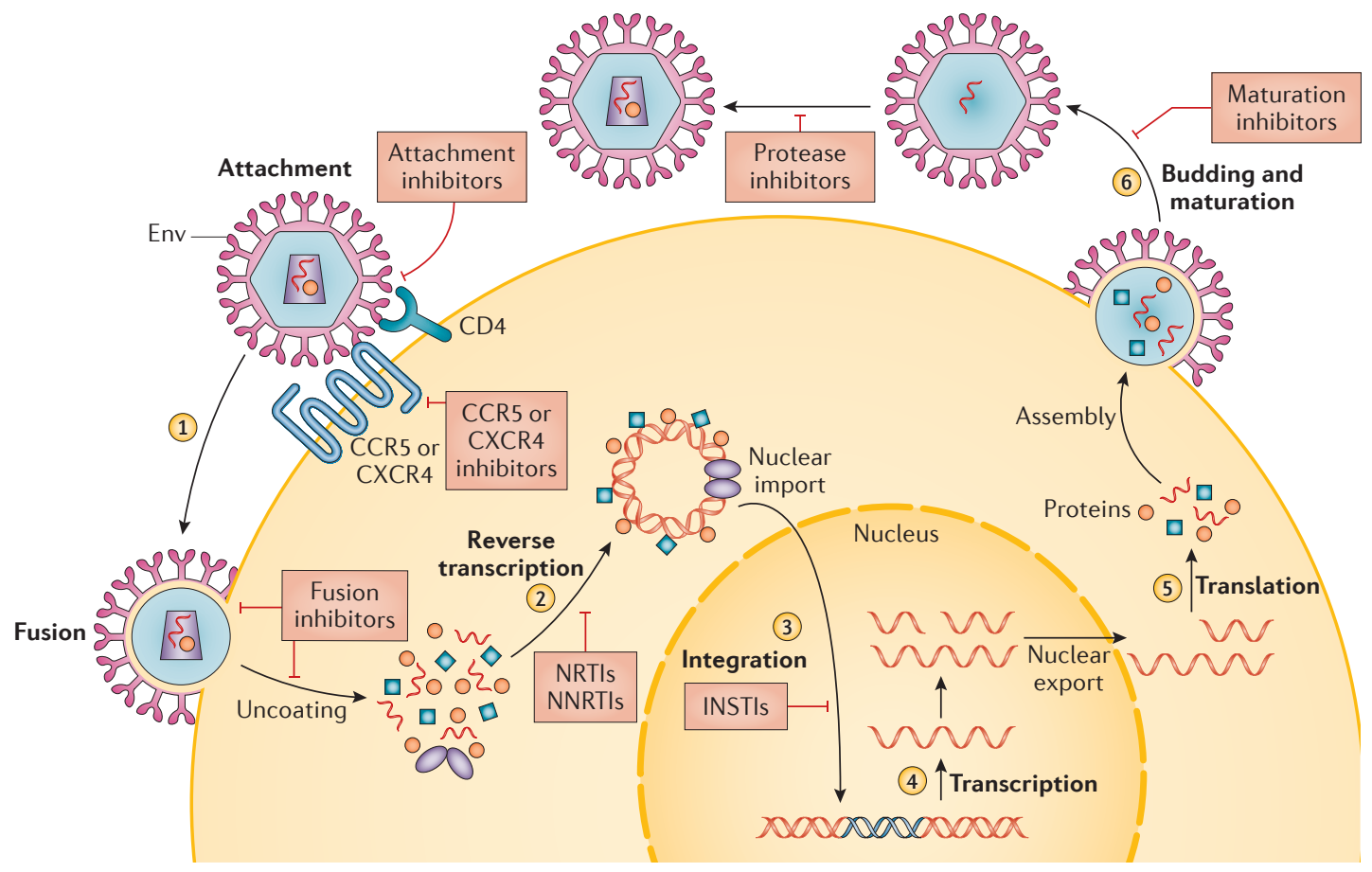

Figure 4 | The HIV life cycle. HIV enters its target cells via CD4 and either CC-chemokine receptor 5 (CCR5) or CXC-chemokine receptor 4 (CXCR4) through interaction with envelope (Env) glycoprotein (step 1). After fusion and uncoating, the viral RNA is then reverse transcribed into DNA (step 2). The ensuing pre-integration complex is imported into the nucleus, and the viral DNA is then integrated into the host genome (step 3). Mediated by host enzymes, HIV DNA is transcribed to viral mRNAs (step 4). These mRNAs are then exported to the cytoplasm where translation occurs (step 5) to make viral proteins and eventually mature virions (step 6). Each step - HIV entry, reverse transcription, integration and protein maturation - in the HIV life cycle is a potential target for antiretroviral drugs ${ }^{251}$. INSTI, integrase strand transfer inhibitor; NNRTI, non-nucleoside reverse transcriptase inhibitor; NRTI, nucleoside reverse transcriptase inhibitor. Figure modified from REF. 252, Nature Publishing Group. 


\section{Box 4 | Elite and post-treatment controllers}

The steady-state level of viraemia in established untreated disease (the viral load set point) varies by several orders of magnitude between individuals. A small subset perhaps $<1 \%$ - are able to naturally control HIV to levels that are undetectable with conventional assays ( $<50$ copies RNA per $\mathrm{ml}$ in the blood). Accordingly, these so-called elite controllers have invited intense interest in the research community ${ }^{12}$. Careful studies of their genetics have revealed strong enrichment of certain human leukocyte antigen (HLA) class I types (which present antigens to $C D 8^{+} T$ cells), and to a lesser extent HLA class Il types (which present antigens to $C D 4^{+} T$ cells), and virus control ${ }^{72,73,232}$. Functional studies of cells obtained from controllers and non-controllers support a central role of HIV-specific CD8 ${ }^{+} \mathrm{T}$ cells in controlling HIV infection ${ }^{233-235}$. The effect of HLA genetic variation might also be owing to its role in binding to the killer-cell immunoglobulin-like receptors (KIRs) on natural killer cells; the KIR gene also demonstrates a genetic association with steady-state viraemia during untreated HIV infection ${ }^{236}$. Although potent $\mathrm{CD} 8^{+} \mathrm{T}$ cells could mediate control of HIV infection in some individuals, many controllers lack evidence of strong $\mathrm{CD} 8^{+} \mathrm{T}$ cell activity ${ }^{237}$. Other potential mechanisms of control include acquisition of viruses that are less able to replicate (reduced viral fitness) ${ }^{238}$ and inherent cellular restriction to infection ${ }^{239,240}$. A clinical phenotype has been identified in which individuals with early HIV infection initiated antiretroviral therapy (ART), remained on ART for several years and subsequently interrupted therapy without experiencing rebound in viraemia. These post-treatment controllers are considered a potential model for treatment-mediated 'cure'. In contrast to elite controllers, post-treatment controllers lack evidence of CD8 ${ }^{+}$ T cell-mediated control. Instead, they tend to be characterized by very low HIV DNA levels (the reservoir) and low immune activation ${ }^{217}$. in analyses of the correlation of drug levels in the blood with efficacy in trials ${ }^{146}$. One trial of 'on-demand' (rather than continuous) pre-exposure prophylaxis with dosing before and after anal sex showed high levels of efficacy ${ }^{146}$. The $\mathrm{WHO}^{147}$ and the Centers for Disease Control and Prevention ${ }^{148,149}$ recommend that daily TDF/FTC preexposure prophylaxis be given to individuals at high risk of acquiring HIV infection through sexual exposure or injection drug use. Other prophylaxis formulations are currently being explored, including long-acting injectable agents and vaginal rings ${ }^{150-152}$. If proven successful, these agents could be combined with hormonal contraception, perhaps reducing the perceived stigma of taking an HIV prophylactic regimen.

Access to pre-exposure prophylaxis can be limited if providers are not comfortable or willing to prescribe the drugs, or if health programmes are unable to help to pay for them. Some providers have expressed reluctance to prescribe pre-exposure prophylaxis because of concerns that poor adherence will limit effectiveness and lead to higher rates of antiretroviral resistance. Some have also suggested that pre-exposure prophylaxis might lead to decreased condom use and increase the rate of sexually transmitted infections ${ }^{153}$. These negative consequences have not yet been seen.

When available, information about the HIV clinical status (for example, viral load) and treatment regimen (for example, the resistance profile) of the index case can be useful in choosing a post-exposure prophylactic regimen. The US Public Health Service updated its recommendations in 2013 to include three-drug or four-drug regimens in the post-exposure setting ${ }^{136}$. Since 1999, the Centers for Disease Control and Prevention has identified only one confirmed case of occupationally acquired HIV infection ${ }^{137}$, probably reflecting the efficacy of post-exposure prophylaxis.

Pre-exposure prophylaxis. For individuals known to be at high risk of becoming infected with HIV, using antiretroviral drugs before an exposure ('pre-exposure prophylaxis') can provide substantial protection. The most closely studied regimen is daily oral tenofovir disoproxil fumarate co-formulated with emtricitabine (TDF/ FTC). Both agents are nucleoside analogues that inhibit viral replication. Daily oral TDF/FTC in an uninfected person reduces HIV acquisition by as much as $86 \%$ in men who have sex with men ${ }^{138}$ and $76 \%$ in heterosexual serodiscordant couples ${ }^{139}$. Other trials have demonstrated lower levels of efficacy ${ }^{140,141}$ and some have failed to demonstrate any efficacy ${ }^{142,143}$. These conflicting results seem to be due to poor adherence to antiretroviral drugs. Indeed, modelling based on measurement of drug levels in the blood and mucosal tissue suggest that very high levels of efficacy (>90\%) can be achieved with high levels of adherence ${ }^{144}$. Given that TDF concentrates in vaginal tissue at levels that are 10-100-times lower than rectal tissue $^{145}$, strict adherence to daily pre-exposure prophylaxis might be required to prevent HIV acquisition in women. By contrast, less than daily dosing might be protective in men who have sex with men, as demonstrated
$H I V$ vaccine. Among the many challenges in developing a preventive HIV vaccine is the lack of a known correlate of protection; despite a robust immune response against HIV, infected individuals do not spontaneously eliminate the virus or its detrimental effects, as occurs with many other infectious diseases. Given that successful infection of $\mathrm{CD}^{+} \mathrm{T}$ cells can lead to latent infection (which we discuss below) in a manner that is impervious to immune responses or ART, it is likely that immune responses that prevent the initial integration of virus, such as antibodymediated defences, will be required to prevent infection. The development of protective antibodies through vaccination is challenging given the substantial sequence diversity in envelope proteins, glycosylation of envelope antigens that shield conserved epitopes from immune responses and variable regions that stimulate immunodominant but non-protective immune responses. It is also possible that ongoing exposure to viral antigens will be required to generate a robust immune response that is capable of protecting against infection ${ }^{154,155}$. Vaccines that clear or control HIV after infection has occurred are also being pursued ${ }^{156}$.

There have been five efficacy trials of HIV vaccine candidates, with only one - the RV144 trial - showing evidence of protection. This trial assessed a combination HIV vaccine (canarypox vector with protein subunit boost) and resulted in a $31 \%$ reduction in HIV acquisition among 16,000 Thai men and women over a 3.5-year period $^{157}$. Analysis of data from this trial suggested that non-neutralizing antibodies, acting by a different mechanism, may have been responsible for protection. Specifically, IgG antibody against a particular part of the outer coat of the virus - namely, the V1V2 region of envelope - was associated with reduced HIV acquisition, with a $48 \%$ efficacy against viruses that matched 
the vaccine at a single amino acid in this region ${ }^{158}$. Interestingly, high titres of IgA antibodies were associated with reduced efficacy; additional analyses suggest that these antibodies can interfere with HIV-specific IgG antibodies by blocking their ability to mediate killing of infected cells through antibody-dependent cell-mediated cytotoxicity. These data provide proof of principle that a protective HIV vaccine can be developed and demonstrate the potential importance of non-neutralizing antibodies in protection.

To achieve higher levels of protection, new strategies are being evaluated (for example, see www.avac.org, www.hvtn.org and www.iavi.org). These include later boosting, inducing neutralizing antibodies and generating a more-balanced cellular immune response. Recently, a growing family of broadly neutralizing antibodies have been isolated from a subset of individuals infected with HIV; efforts to induce these antibodies through active immunization have so far been unsuccessful ${ }^{155}$. Several efficacy trials are anticipated to begin over the next several years, each testing a different approach.

Combination prevention. As all of the prevention strategies now being developed will likely prove to be only partially effective, combination approaches will probably be needed. Some combinations might prove to be synergistic and have a greater affect than might be expected based on our understanding of individual efficacy (FIG. 6). For example, modelling studies suggest that combining a circumcision programme for HIV-negative men with a programme aimed at reducing sex without condom use in the same community would decrease

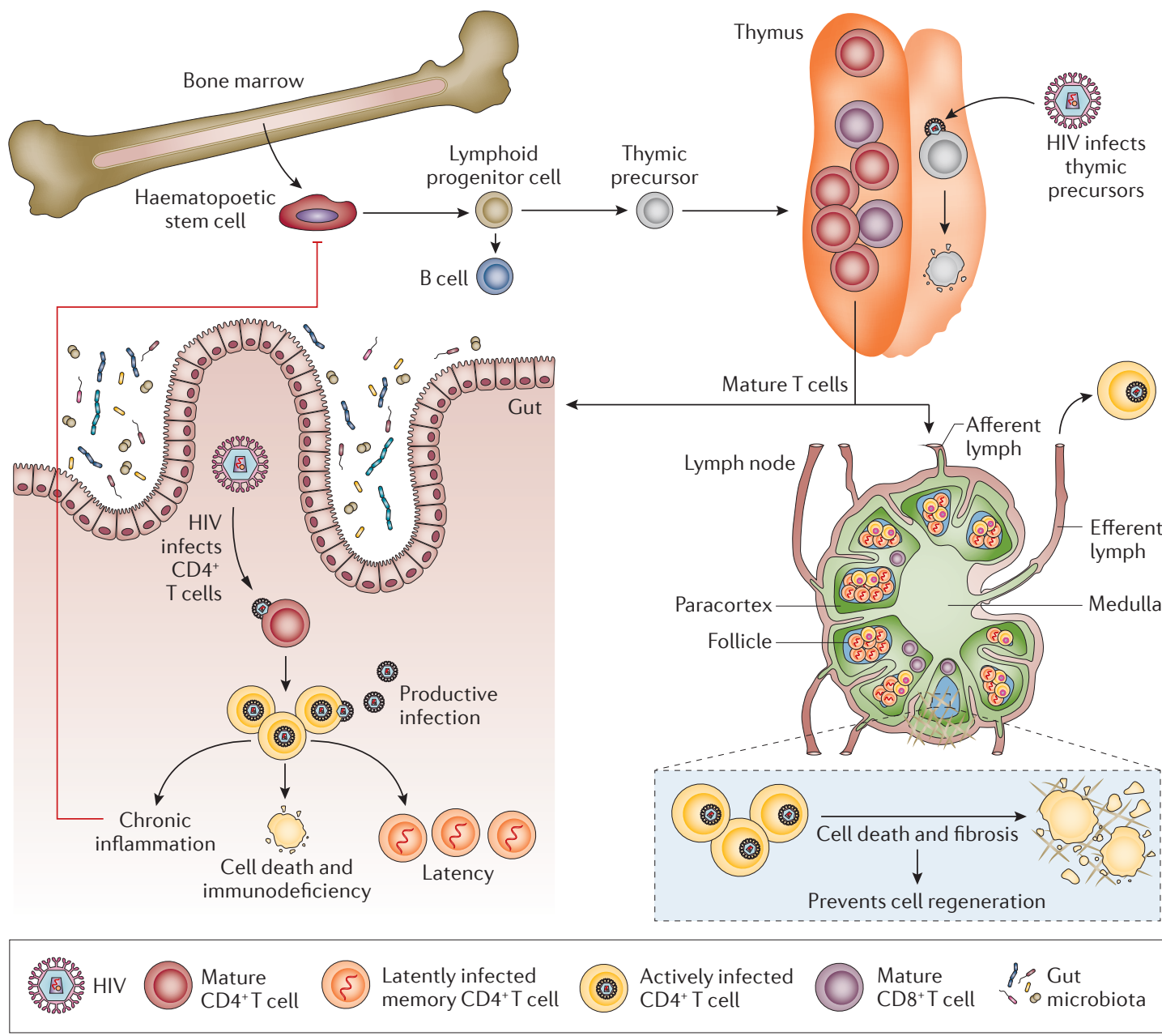

Figure 5 | T cell depletion. HIV infection has a profound and complex effect on the immune system. HIV preferentially infects activated $\mathrm{CD} 4^{+} T$ cells and causes death of these cells through direct (cytopathic) or indirect mechanisms. Much of this cell death occurs within mucosal tissues ${ }^{86}$ (primarily in the gut) during the first few weeks of the infection ${ }^{252}$. HIV can also infect the thymus ${ }^{253}$, leading to accelerated thymic loss (beyond what is observed with normal ageing), which contributes to the regenerative failure of $T$ cells. In the secondary lymph nodes, rapid loss of infected CD4 ${ }^{+} T$ cells also occurs. The immunodeficiency that emerges as a result of this T cell depletion results in excess pathogen load and chronic inflammation ${ }^{86}$, which in turn exacerbates harm to the lymphoid system by promoting, for example, tissue fibrosis in the lymph nodes ${ }^{22}$. The chronic inflammatory process stimulates immunoregulatory responses that blunt T cell function ${ }^{254}$ and might also impair haematopoiesis directly or indirectly ${ }^{255}$, although the mechanisms underlying the effects on the bone marrow are unclear. 


\section{Table 1 | Risk of HIV acquisition from an HIV-infected source ${ }^{\star, \neq}$}

\begin{tabular}{|c|c|c|}
\hline Exposure route & $\begin{array}{l}\text { Infections per } \\
10,000 \text { contacts }\end{array}$ & $95 \% \mathrm{Cl}$ \\
\hline \multicolumn{3}{|l|}{ Parenteral exposure } \\
\hline Blood transfusion & 9,250 & $8,900-9,610$ \\
\hline Injection drug use with sharing equipment & 63 & $41-92$ \\
\hline Needle stick injury & 23 & $0-46$ \\
\hline \multicolumn{3}{|l|}{ Sexual exposure without condom use } \\
\hline Receptive anal sex & 138 & $102-186$ \\
\hline Insertive anal sex & 11 & $4-28$ \\
\hline Receptive vaginal sex & 8 & $6-11$ \\
\hline Insertive vaginal sex & 4 & $1-14$ \\
\hline Receptive oral sex & Low & $0-4$ \\
\hline Insertive oral sex & Low & $0-4$ \\
\hline \multicolumn{3}{|l|}{ Vertical transmission } \\
\hline At the time of birth & 2,260 & $1,700-2,900$ \\
\hline
\end{tabular}

new HIV infections to a greater extent than expected from each intervention individually ${ }^{159}$. Large-scale efficacy trials of combination prevention strategies are currently underway ${ }^{160}$.

\section{Management}

The development of combination ART is often touted as one of the greatest achievements of modern medicine. When given to adherent and motivated individuals, contemporary combination regimens reduce the level of viraemia by several orders of magnitude in a matter of weeks. The degree of viral suppression is so great that viral evolution and the emergence of drug-resistant mutations are prevented. In principle, these regimens should work indefinitely. In the absence of viral replication, the immune system recovers much of its lost function and AIDS is prevented.

ART is not always fully effective. The development and transmission of drug resistance remains a major concern (see below). Even if durable viral suppression is achieved, many individuals fail to restore optimal immune function, even after several years of ART (BOX 5). Finally, all drugs have potential for short-term and long-term toxicities. Even subtle toxicities can have a large cumulative effect given that these drugs must be administered for life.

\section{Antiretroviral drugs}

Approximately 25 unique antiretroviral drugs have been approved for use in adults by the US and European regulatory agencies. These drugs span five therapeutic classes, each targeting a unique step in the life cycle of the virus (FIG. 4; TABLE 3). Antiretroviral drugs are generally first developed and approved for the management of HIV infection in adults; it can take several years for these drugs to be developed in the paediatric population (BOX 3). Although industry continues to develop novel therapeutic approaches, the lack of major unmet needs with existing options had led to a dramatic decline in pace of investment in the past few years. Accordingly, the available combination approaches will not likely change dramatically over the next several years (and perhaps decades).

Nucleoside reverse transcriptase inhibitors. Nucleoside reverse transcriptase inhibitors (NRTIs) act by blocking reverse transcriptase. These drugs are analogues of natural nucleosides and nucleotides, and are preferentially incorporated into HIV DNA, leading to termination of DNA synthesis (FIG. 4). For historical reasons, most new drugs have been studied and approved for initial therapy as a component of a three-drug regimen containing two nucleoside or nucleotide analogues and a potent third drug from another class. Currently, only two first-line nucleoside or nucleotide 'backbone' regimens are recommended: tenofovir and emtricitabine or abacavir and lamivudine (both are largely used as fixeddose, once-daily regimens). Tenofovir is associated with subtle but consistent declines in renal function and bone function; Fanconi syndrome is also a rare complication. Tenofovir alafenamide fumarate (TAF) is a recently developed prodrug of tenofovir that demonstrates less kidney and bone toxicity. TAF may have greater penetration into lymphoid tissues (where most HIV resides) than tenofovir and is expected to replace tenofovir in most future regimens. Abacavir is associated with potentially life-threatening allergic reactions in individuals who harbour the HLA-B ${ }^{\star} 5701$ allele; testing for this allele is required ${ }^{161}$. Observational data from large clinical cohorts indicate that abacavir might be associated with an increased risk of cardiovascular disease ${ }^{162}$, particularly in those with multiple risk factors; whether this association is real is the focus of ongoing debate.

The nucleoside analogues zidovudine (commonly known as AZT) and stavudine are no longer widely used in resource-rich settings. These drugs have been associated with several potential complications, including anaemia (zidovudine), neuropathy (stavudine), hepatic steatosis (both), lactic acidosis (both) and potentially disfiguring loss of body fat known as lipoatrophy (zidovudine and, to a greater extent, stavudine). Stavudine was formerly part of the WHO-recommended first-line regimen and was widely used in the past, but is now being phased out owing to these toxic effects. Zidovudine is still used in second-line regimens in sub-Saharan Africa and elsewhere.

Given the persistent concerns that the entire drug class can cause subtle but irreversible toxicities, many research groups have attempted to construct nucleoside analogue-sparing regimens. Regimens in which only a protease inhibitor is used have proven to be effective, but less so than those that also included nucleoside or nucleotide analogues. Other regimens involving potent drugs but excluding nucleoside or nucleotide analogues have proven to be less effective than expected, particularly at high viral loads ${ }^{163}$. A compromise in which only a single well-tolerated nucleoside analogue (lamivudine or emtricitabine) is used as the backbone seems promising ${ }^{164}$. 
Integrase strand transfer inhibitors. Integrase strand transfer inhibitors prevent the HIV genome from being integrated into the host genome (FIG. 4). As a class, these drugs are potent, well tolerated and safe. Dolutegravircontaining regimens have been consistently found to be superior or at least non-inferior to other first-line regimens ${ }^{165,166}$; dolutegravir is administered once daily in treatment-naive individuals, has limited toxicity and limited drug-drug interactions. Raltegravir has comparable activity to dolutegravir ${ }^{167}$, and when both toxicity and virological efficacy are considered, is more effective than other common first-line options ${ }^{168,169}$. However, it has to be administered twice daily. Elvitegravir is rapidly metabolized by the liver and requires co-administration with a pharmacological booster (cobicistat) that prevents hepatic clearance. Cobicistat inhibits the renal secretion of creatinine, making it difficult to monitor kidney function in a clinical setting. The fixed dose combination of elvitegravir, cobicistat, tenofovir and emtricitabine is not recommended for patients with kidney dysfunction. Drug-drug interactions are common with cobicistat. In the most recent US Department of Health and Humans Services treatment guidelines ${ }^{170}$, four of the five recommended first-line regimens include an integrase strand transfer inhibitor.

Non-nucleoside reverse transcriptase inhibitors. Nonnucleoside reverse transcriptase inhibitors (NNRTIs) inhibit reverse transcriptase in a manner that is very different from the NRTIs. These drugs bind to a pocket near the active site, which causes a conformational change of the enzyme and inhibition of reverse transcription (FIG. 4). As a class, the NNRTIs are potent, safe and easy to produce (making them affordable). When used in adherent patients as part of three-drug regimens, these drugs have proven to be very effective. Efavirenz has in the past been the most widely used drug in highincome countries. Although potent and generally well tolerated, the drug has some central nervous system toxicity and might increase the risk of depression and suicidality ${ }^{171}$. A lower dose might prove to be as effective and better tolerated ${ }^{172}$. Nevirapine was part of the first WHO-recommended regimen in the past and has been widely used in many low-income countries owing to its low cost and availability as a generic drug. Nevirapine is effective, but can cause severe hepatotoxicity and rash when used in patients with higher $\mathrm{CD} 4^{+} \mathrm{T}$ cell counts; the drug should not be initiated in women with $\mathrm{CD} 4^{+}$ $\mathrm{T}$ cell counts of $>250$ cells per $\mu \mathrm{l}$ or men with counts of $>400$ cells per $\mu$ l. Rilpivirine seems to be the besttolerated NNRTI, but is less effective in individuals with high plasma HIV RNA levels ${ }^{173}$, and is only recommended for individuals with a viral load of $<100,000$ RNA copies per $\mathrm{ml}$ and $\mathrm{CD} 4{ }^{+} \mathrm{T}$ cell counts of $>200$ cells per $\mu 1^{174}$. Etravirine is approved for twice-daily dosing, but can probably be administered once daily ${ }^{175}$. The drug is generally only used after others have failed.

Protease inhibitors. As the virion matures and buds from the cell, long polypeptide chains are enzymatically cleaved into mature functional proteins by the HIV enzyme protease. Protease inhibitors block this late step in the life cycle of the virus (FIG. 4). When used with two nucleoside analogues, protease inhibitors are also highly effective. These drugs are rapidly metabolized by the liver and are often co-administered with a drug that inhibits these metabolic pathways (ritonavir or cobicistat, referred to as pharmacological 'boosters'). These drugs generally cause mild gastrointestinal symptoms and dyslipidaemia. Several protease inhibitors have been associated with increased risk of cardiovascular disease ${ }^{176}$, although this has not been demonstrated with darunavir and atazanavir, two of the more widely used drugs.

Owing to their high manufacturing costs, protease inhibitors are generally only used in low-income regions in second-line and third-line regimens. Atazanavir has been a popular protease inhibitor as it has fewer gastrointestinal side effects than many other protease inhibitors, but it was discontinued at a higher rate than raltegravir or darunavir in a recent randomized clinical trial,

\begin{tabular}{|c|c|c|c|}
\hline Test type & Measurement & Eclipse period ${ }^{\ddagger}$ & Notes \\
\hline First generation & $\lg G$ against viral lysate & 4-7 weeks & $\begin{array}{l}\text { - HIV-1 western blot and HIV-1 } \\
\text { immunofluorescence assay } \\
\text { - Assay is being phased out }\end{array}$ \\
\hline Second generation & $\begin{array}{l}\text { IgG against synthetic peptides } \\
\text { or recombinant proteins }\end{array}$ & 4-7 weeks & $\begin{array}{l}\text { - Most rapid tests use } \\
\text { second-generation technology } \\
\text { - Can differentiate HIV-1 infection } \\
\text { from HIV-2 infection }\end{array}$ \\
\hline Third generation & $\begin{array}{l}\operatorname{lgG} \text { and } \lg \mathrm{M} \text { against synthetic } \\
\text { peptides or recombinant proteins }\end{array}$ & $3-5$ weeks & $\begin{array}{l}\text { - Same technology as fourth- } \\
\text { generation assay, but is less sensitive } \\
\text { - Assay is being phased out }\end{array}$ \\
\hline Fourth generation & $\begin{array}{l}\lg G \text { and } \lg M \text { against synthetic } \\
\text { peptides or recombinant proteins, } \\
\text { and monoclonal antibodies } \\
\text { against p24 }\end{array}$ & 2-3 weeks & $\begin{array}{l}\text { - Recommended as an initial } \\
\text { diagnostic test for HIV infection }\end{array}$ \\
\hline Nucleic acid testing & Detection of HIV-1 RNA & 10 days & - Might not detect HIV-2 infection \\
\hline
\end{tabular}

HIV-1, HIV type 1; HIV-2, HIV type 2. *Laboratory tests used by the US Centers for Disease Control and Prevention. ${ }^{*}$ Defined as the time period between HIV infection and a positive test result; results represent median values, and individual results can vary. 


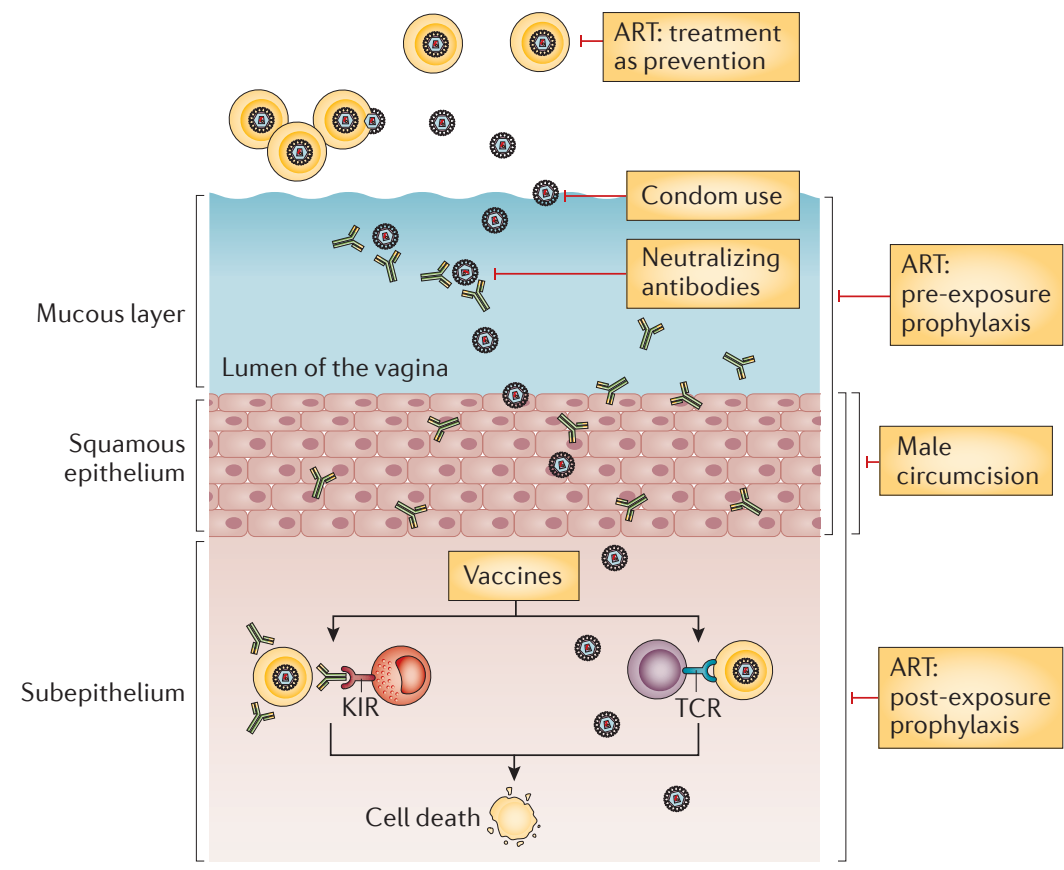

$\begin{array}{lll}\text { Actively infected } & \text { Mature } \\ C D 8^{+} \text {T cell } & \text { CD4 } & \text { Natural } \\ \text { killer cell } & \text { Antibody }\end{array}$

Figure $6 \mid$ HIV prevention strategies. The sexual transmission of HIV infection at the mucosal surfaces can be prevented at multiple points. Antiretroviral therapy (ART) in the potential source partner prevents infectious virus particles from being produced (treatment as prevention). Condom use provides a mechanical barrier that prevents sexual transmission. Male circumcision of an uninfected male also protects against acquisition of HIV infection, presumably because of changes in the frequency of potential target cells in the penile skin. Neutralizing antibodies that are administered passively or are generated by a vaccine can bind to the transmitted virus at the mucosal surface, preventing infection of target cells. Antibodies can also stimulate antibody-dependent cell-mediated cytotoxity and clearance of infected cells. ART before exposure (pre-exposure prophylaxis) also prevents infection, whereas ART soon after an exposure (post-exposure prophylaxis) prevents infection and/or spread. Vaccine-mediated T cell responses are unlikely to prevent infection alone but will contain the size of the initial infection, leading to durable control. In combination, partially effective strategies might fully prevent HIV infection. KIR, killer-cell immunoglobulin-like receptor; TCR, T cell receptor.

primarily because of hyperbilirubinaemia ${ }^{168}$. Darunavir (when boosted with ritonavir or cobicistat) is also popular and has comparable efficacy to other first-line regimens ${ }^{168}$, although one study found it to be less effective than dolutegravir ${ }^{165}$. In the most recent US Department of Health and Humans Services treatment guidelines, darunavir was the only recommended first-line protease inhibitor $^{170}$.

Entry inhibitors. Entry inhibitors prevent HIV from entering the cell (FIG. 4). For example, maraviroc binds to CCR5 and prevents R5 virus variants from entering the cells. The drug requires a highly technical test to ensure that patients do not harbour virus variants that use CXCR4, and the drug has to be administered twice daily. Enfuvirtide binds to HIV directly; this drug is rarely used as it is expensive and must be injected twice daily.

\section{When to start ART}

Therapy is strongly indicated in those with advanced immunodeficiency $\left(\mathrm{CD} 4^{+} \mathrm{T}\right.$ cell counts of $<200$ cells per $\mu \mathrm{l})^{177}$. On the basis of a series of randomized clinical trials that directly or indirectly compared immediate with deferred therapy among those with moderate-stage disease $^{178,179}$, as well as a wealth of supporting observational data, all guidelines have recommended ART for those who have a CD $4^{+} \mathrm{T}$ cell count of $<350$ cells per $\mu \mathrm{l}$, and most guidelines recommend ART for those with a count of $<500$ cells per $\mu$ l.

The optimal time to start ART has been debated for many years. Some expert panels have argued that as AIDS event rates are low in people with high $\mathrm{CD} 4^{+} \mathrm{T}$ cell counts, the potential toxicities associated with ART could outweigh any benefit and therapy should be deferred ${ }^{180}$. Other groups have argued that ART should be recommended in early stage disease because it prevents irreversible harm to the immune system and perhaps other organ systems, improves qualify of life and reduces the risk of transmission ${ }^{174}$. To address this ongoing controversy, several large randomized clinical trials have been performed. In a study based in Côte d'Ivoire, west Africa (Temprano ANRS 12136) ${ }^{181}$, approximately 2,000 untreated adults (mostly women) with a $\mathrm{CD} 4^{+} \mathrm{T}$ cell count between 350 cells and 800 cells per $\mu$ l were randomly assigned to immediate versus delayed (based on local WHO guidelines) ART. Early ART was associated with a $44 \%$ decrease in severe HIV morbidity ${ }^{181}$. The International Network for Strategic Initiatives in Global HIV Trials (INSIGHT) network performed a randomized study of early versus deferred ART in 4,685 asymptomatic adults with a CD4 $4^{+} \mathrm{T}$ cell count of $>500$ cells per $\mu \mathrm{l}$ (the Strategic Timing of AntiRetroviral Treatment (START) study). The group assigned to receive deferred ART were recommended to start ART when it became apparent that the more-aggressive use of ART was associated with a $57 \%$ decrease in the risk of developing serious illness or death $^{182}$. The study was performed in $>35$ countries in all income brackets (low, middle and high), and the benefit of early ART was consistently observed in all regions.

ART is expected to be recommended for anyone with HIV infection. However, individuals who are not ready to commit to therapy should not be treated until they feel that they can adhere to therapy (to avoid promoting virus drug resistance), or until $\mathrm{CD} 4^{+} \mathrm{T}$ cell counts decline to levels that make waiting too risky in terms of developing AIDS-related complications. Therapy can also be reasonably deferred for those rare elite controllers, although recent uncontrolled studies suggest that they too might benefit from therapy in terms of chronic inflammation ${ }^{183}$.

Regardless of disease state, ART is generally recommended in HIV-discordant couples, HIV-positive women who are pregnant or who are breastfeeding, individuals co-infected with hepatitis B and in the WHO guidelines for all HIV-positive children under 5 years of age.

\section{Antiretroviral drug resistance}

The vast majority of individuals who are infected with 'wild-type' HIV and who are able to adhere to a 
contemporary therapeutic regimen are able to fully suppress HIV replication ${ }^{184}$. However, incomplete adherence to therapy results in ongoing HIV replication in the presence of drug, which invariably leads to the selection of mutations within the virus that confer resistance to antiretroviral drugs. The rate at which resistance emerges depends in large part on the selective advantage that the ensuing mutation or mutations confer to the virus. Mutations that reduce the inherent capacity of the virus to replicate (viral fitness) ${ }^{185}$ and/ or mutations that only have subtle effects on drug susceptibility are slow to emerge ${ }^{186}$. Mutations have been shown to emerge rapidly for the NNRTIs, as well as the NRTIs lamivudine and emtricitabine. Mutations emerge more slowly for many of the NRTIs (including tenofovir and abacavir) and some integrase strand transfer inhibitors (for example, raltegravir), but rarely for boosted protease inhibitors and the integrase strand transfer inhibitor dolutegravir.

Once drug resistance emerges, it can be transmitted to others. The prevalence of drug resistance in transmitted variants has been in the range of $5-15 \%$ for high-income countries ${ }^{187-189}$, with rates generally higher in the United States than in Europe ${ }^{190}$. The prevalence of transmitted drug resistance has generally been low in low-income and middle-income countries, but has increased in recent years as the penetration of therapy into these regions has increased ${ }^{189}$. One meta-analysis showed that the prevalence of transmitted drug-resistant HIV doubled between 2004-2008 and 2009-2013 (REF. 190). As viral load monitoring is not routinely carried out in many low-income countries, concerns have been raised that people will be maintained on partially effective therapy for prolonged periods of time, which could eventually lead to a major epidemic of transmitted resistance.

\section{Box 5 | Immunological failure}

By preventing HIV replication, antiretroviral therapy (ART) prevents and often reverses HIV-mediated damage to the immune system. Indeed, the majority of individuals who initiate and remain on suppressive therapy eventually achieve a normal or near-normal peripheral blood CD4 ${ }^{+}$T cell count $(\geq 500 \text { cells per } \mu \text { l) })^{241}$. Regardless, a substantial minority of individuals whose virus is well controlled have persistently low $\mathrm{CD} 4^{+} \mathrm{T}$ cell counts; this phenomenon is often referred to as immunological failure or non-response, and is defined by having a low $C D 4^{+} T$ cell count $(<350$ cells per $\mu$ lafter a defined period) or a low rate of $\mathrm{CD} 4{ }^{+} \mathrm{T}$ cell re-accumulation ${ }^{170}$. Persistent $\mathrm{T}$ cell activation, haematopoietic stem cell failure, thymic dysfunction, residual low-level HIV replication and other factors have been implicated in non-response ${ }^{198}$. A low $C D 4^{+} \mathrm{T}$ cell count on therapy has been associated with increased risk of cardiovascular disease, cancer and other co-morbidities ${ }^{242,243}$. Starting therapy before $C D 4^{+} T$ cell counts fall $<200$ cells per $\mu$ l largely protects against subsequent immunological failure. Other forms of immunological dysfunction often persist during therapy. For example, the peripheral $\mathrm{CD} 8^{+} \mathrm{T}$ cell count is often increased during untreated HIV infection and, to a lesser degree, in antiretroviral-treated disease. A persistent ratio of $\mathrm{CD} 4^{+}$to $\mathrm{CD} 8^{+} \mathrm{T}$ cells is very common in HIV infection and is a poor prognostic marker ${ }^{244}$. Many markers of chronic inflammation - reflecting activation of the innate immune system - are also often increased in treated disease (as compared to the uninfected state) and are associated with poor clinical outcome ${ }^{195,245,246}$. Despite intensive investigation, no way is known to reverse any of these immunological abnormalities ${ }^{170}$, although starting therapy early in the disease course limits the development of irreversible immunological damage ${ }^{247,248}$.

\section{Quality of life}

Health-related quality of life is a multidimensional concept that incorporates factors such as physical, cognitive, emotional and social functioning. Many factors common among those with HIV infection that could affect quality of life (FIG. 7) include: polypharmacy, treatment toxicity, poor mental health related to the burden of a lifelong chronic condition, substance abuse, social isolation and stigma. Indeed, as compared with the general population, people diagnosed with HIV infection have a lower health-related quality of life ${ }^{191}$. Importantly, this reduced quality of life has been found to be independent of other risk factors, including socioeconomic status and access to health care, and occurs across all viral load and $\mathrm{CD} 4^{+}$ $T$ cell strata. The effect was greatest in those people who were diagnosed for the longest time ${ }^{191}$.

Little data are available to help us understand the extent to which reduced quality of life in people living with HIV infection can be directly attributed to adverse effects of antiretroviral drugs. As mentioned above, some, if not all, nucleoside analogues can cause disfiguring and irreversible loss of body fat (lipoatrophy). All antiretroviral drugs can cause mild adverse effects. As these drugs must be taken daily for an individual's lifetime, even mild adverse effects can cumulatively contribute to a poor quality of life. Common effects include mild depression and abnormal dreams (with efavirenz), gastrointestinal symptoms (with ritonavirboosted protease inhibitors and tenofovir) and rash (many drugs).

\section{Co-morbidities and ageing}

Although most of the traditional complications associated with AIDS can now be easily prevented with ART, some residual morbidity risk persists, including cardiovascular disease, osteopenia and osteoporosis, some cancers, liver dysfunction, renal dysfunction and neurocognitive disease ${ }^{192,193}$. In many studies, when those with HIV infection are compared with age-matched individuals without HIV infection, the excess risk is comparable to other traditional risk factors such as hypertension and hyperlipidaemia ${ }^{194}$. Much of this excess risk is attributable to a greater burden of traditional risk factors in HIV-positive individuals - particularly tobacco use and obesity. However, many factors are present because of the HIV infection, including persistent immune dysfunction and inflammation ${ }^{195}$ and antiretroviral drug toxicity ${ }^{162,196,197}$.

In addition to these concerns about co-morbidity, concerns have been raised in the popular and scientific press that HIV infection and/or its treatment affect ageing. The notion that the biology of ageing might be affected by HIV infection is perhaps not surprising, as many of the biological factors known to influence cell and tissue ageing are common in this disease (such as mitochondrial toxicity, metabolic abnormalities, telomere shortening, inflammation and stem cell dysfunction $)^{198}$. Many of the clinical factors known to adversely affect healthy ageing are also common in those with HIV infection (for example, multi-morbidity, polypharmacy, poverty, substance abuse and social isolation) ${ }^{199}$. Some 


\begin{tabular}{|c|c|c|}
\hline Class & Drug & Notes \\
\hline \multirow[t]{5}{*}{ NRTI } & $\begin{array}{l}\text { Lamivudine and } \\
\text { emtricitabine }\end{array}$ & $\begin{array}{l}\text { - Well tolerated } \\
\text { - A component of all recommended regimens } \\
\text { - Active against HBV }\end{array}$ \\
\hline & Tenofovir & $\begin{array}{l}\text { - Can cause kidney toxicity (proximal tubulopathy) and bone toxicity (loss of bone } \\
\text { mineral density) } \\
\text { - Active against HBV }\end{array}$ \\
\hline & Abacavir & $\begin{array}{l}\text { - Requires pre-treatment testing for HLA-B*5701 allele to prevent hypersensitivity } \\
\text { reaction } \\
\text { - Might increase the risk of myocardial infarction }\end{array}$ \\
\hline & Zidovudine & $\begin{array}{l}\text { - Causes anaemia, gastrointestinal adverse effects and lipoatrophy } \\
\text { - Potential for lactic acidosis and/or hepatic steatosis } \\
\text { - No longer recommended in most regions of the world, but is often used for cost } \\
\text { reasons in resource-limited areas }\end{array}$ \\
\hline & Stavudine & $\begin{array}{l}\text { - Causes peripheral neuropathy, pancreatitis and lipoatrophy } \\
\text { - Potential for lactic acidosis and/or hepatic steatosis } \\
\text { - No longer recommended, but is often used for cost reasons in resource-limited areas }\end{array}$ \\
\hline \multirow[t]{3}{*}{ INSTI } & Dolutegravir & $\begin{array}{l}\text { - Minimal toxicity } \\
\text { - Few drug interactions } \\
\text { - Higher barrier to resistance than other INSTIs }\end{array}$ \\
\hline & Raltegravir & $\begin{array}{l}\text { - Minimal toxicity } \\
\text { - Few drug interactions } \\
\text { - The only commonly used drug that requires twice-daily dosing }\end{array}$ \\
\hline & Elvitegravir & $\begin{array}{l}\text { - Must be administered with a pharmacological 'booster' (cobicistat), resulting in } \\
\text { multiple drug interactions }\end{array}$ \\
\hline \multirow[t]{3}{*}{ NNRTI } & Efavirenz & $\begin{array}{l}\text { - Short-term and long-term CNS toxicity } \\
\text { - Potential for rash } \\
\text { - Long half-life can provide 'forgiveness' for missed doses but increases the risk of } \\
\text { resistance with treatment interruption }\end{array}$ \\
\hline & Nevirapine & $\begin{array}{l}\text { - Potential for severe rash and/or hepatotoxicity, especially in women and patients } \\
\text { with higher } C D 4^{+} \mathrm{T} \text { cell counts } \\
\text { - No longer preferred, but is still commonly used for cost reasons in resource-limited } \\
\text { regions }\end{array}$ \\
\hline & Rilpivirine & $\begin{array}{l}\text { - Well tolerated } \\
\text { - Less effective in patients with high pre-therapy viral loads and/or low } \mathrm{CD} 4^{+} \\
\text {T cell counts } \\
\text { - Must be taken with a meal } \\
\text { - Contraindicated with PPIs, histamine } \mathrm{H} 2 \text { receptor antagonists and antacids }\end{array}$ \\
\hline \multirow[t]{2}{*}{$\begin{array}{l}\text { Protease } \\
\text { inhibitor }\end{array}$} & Darunavir & $\begin{array}{l}\text { - Must be administered with a pharmacological 'booster' (ritonavir or cobicistat) } \\
\text { - No drug resistance } \\
\text { - Potential for rash } \\
\text { - More gastrointestinal adverse effects than with INSTIs }\end{array}$ \\
\hline & Atazanavir & $\begin{array}{l}\text { - Administration with a pharmacological 'booster' is recommended, but can be } \\
\text { given unboosted } \\
\text { - No drug resistance with failure when boosted } \\
\text { - Causes symptomatic hyperbilirubinaemia in many individuals } \\
\text { - Potential for nephrotoxicity, nephrolithiasis or cholelithiasis } \\
\text { - Decreased absorption with PPIs, histamine } \mathrm{H} 2 \text { receptor antagonists and antacids } \\
\text { - More gastrointestinal adverse effects than with INSTIs }\end{array}$ \\
\hline $\begin{array}{l}\text { Entry } \\
\text { inhibitor }\end{array}$ & Maraviroc & $\begin{array}{l}\text { - Requires a specialized test to confirm that the virus will be susceptible to } \\
\text { drug treatment } \\
\text { - Mostly administered twice daily } \\
\text { - Selects for a potentially more-pathogenic CXCR4-using virus }\end{array}$ \\
\hline
\end{tabular}

CNS, central nervous system; CXCR4, CXC-chemokine receptor 4; HBV, hepatitis B virus; HLA-B`5701, human leukocyte antigen-B*5701; INSTI, integrase strand transfer inhibitor; NNRTI, non-nucleoside reverse transcriptase inhibitor; NRTI, nucleoside reverse transcriptase inhibitor; $\mathrm{PPI}$, proton pump inhibitor.

of the more-common geriatric syndromes, including frailty, seem to be more common in those with HIV disease than in those without the disease; this finding is particularly true for people who are in their sixth and seventh decade of life ${ }^{200}$.

\section{Outlook}

The prevention, management and investigation of HIV infection has and will probably remain vibrant. Within the prevention arena, we have in the past few years witnessed a dramatic shift in prevention research 


\begin{tabular}{|c|c|c|}
\hline & HIV infection & \multirow[b]{2}{*}{$y$} \\
\hline † & $\checkmark$ & \\
\hline $\begin{array}{l}\text { Effects of drug toxicity } \\
\text { - Gastrointestinal distress } \\
\text { - Metabolic abnormalities } \\
\text { - Fat redistribution } \\
\text { - Renal and hepatic dysfunction } \\
\text { - Cognitive adverse effects } \\
\text { - Rash } \\
\text { - Drug-drug interactions }\end{array}$ & \begin{tabular}{|l|} 
Effects on quality of life \\
- Stigma \\
- Burden of chronic \\
illness \\
- Substance abuse \\
- Social isolation \\
- Depression \\
- Polypharmacy
\end{tabular} & $\begin{array}{l}\text { Common co-morbidities } \\
\text { - Cardiovascular disease } \\
\text { - Osteopenia and } \\
\text { osteoporosis } \\
\text { - Cancer } \\
\text { - Liver dysfunction } \\
\text { - Renal dysfunction } \\
\text { - Neurocognitive impairment }\end{array}$ \\
\hline
\end{tabular}

Figure 7| Quality of life impairment in individuals with HIV infection. Individuals infected with HIV may experience effects on their quality of life across several domains. HIV-related symptoms often present in those with low $\mathrm{CD} 4^{+} \mathrm{T}$ cell counts. In addition, mental health can be affected in numerous ways, and antiretroviral drugs can be associated with adverse effects. of male medical circumcision, rapid scale-up of HIV testing, scale-up of ART at a population level and peer support for improving retention on ART. If successful, these strategies, along with continued donor and national funding for HIV programmes, might sustain and advance the delivery of clinical interventions and eventually bring the pandemic under control.

\section{Treatment as prevention trials}

ART can dramatically reduce a person's infectiousness. Providing access to testing and treatment for all individuals within a community could have dramatic effects on public health. At least four community cluster randomized trials are underway in eastern and southern Africa to explore the hypothesis that universal testing and initiation of ART will lead to reductions in the number of new infections at a population level (Sustainable East Africa Research in Community Health $(\text { SEARCH })^{205}$, Population Effects of ART to Reduce HIV Transmission (PopART) ${ }^{160}$, Botswana Combination Prevention Project (BCPP) ${ }^{206}$ and Impact of Immediate Versus South African Recommendations Guided ART Initiation on HIV Incidence (ARNS/TasP) ${ }^{207}$ ). Given the costs involved with universal testing and treatment, national governments and other funders need rigorous demonstration that such investments will have the expected effect on the pandemic.

The proportion of people with HIV infection who are required to be diagnosed, on ART and with viral suppression to achieved 'near elimination' of transmission (that is, $<1$ per 1,000 person years) will vary by setting, but has been estimated to be as high as around $90 \%$ in men who have sex with men in the United Kingdom ${ }^{208}$.

\section{The 90-90-90 programme}

The current scale-up of HIV therapies to sub-Saharan Africa and other regions of the world has delivered ART to $>15$ million people to date. However, major gaps in delivery of HIV services remain. An estimated 30-50\% of people infected with HIV remain undiagnosed ${ }^{14}$, $30 \%$ of patients eligible for treatment do not start in a timely way ${ }^{19}$ and $20-30 \%$ of patients on treatment are not known to be retained in care after 2 years ${ }^{201-203}$. Only $32 \%$ of children with HIV infection are on ART ${ }^{6}$. These gaps are reflected in the still-high death toll: $>1$ million HIV-related deaths occur each year ${ }^{6}$.

To address these gaps, the global community has recently set the ' $90-90-90$ ' goals. By 2020 , it is hoped that $90 \%$ of people with HIV infection will be diagnosed, that $90 \%$ of those diagnosed will be on ART and that $90 \%$ of those on ART will have viral suppression. The fact that perhaps only one-third of the HIV-infected population in the United States are on effective ART demonstrates the ambitious nature of this goal ${ }^{204}$.

The 90-90-90 programme will only be possible through multidisciplinary efforts that seek to encourage testing and to get those infected with HIV to engage with the health care system. Ongoing studies are exploring a wide range of potential programmatic improvements, including SMS text messages to engage patients in antenatal care, conditional cash transfers for uptake

\section{Injectable antiretroviral drugs}

A key limitation of modern ART is that therapy must be taken every day for life. On a community level, delivering drugs to a global population in need has raised numerous logistical challenges. On an individual level, adherence to a daily medication can often be challenging, particularly for individuals living in poverty, who have mental disorders or who are active substance abusers ${ }^{209}$. These concerns also apply to the use of antiretroviral drugs as prevention (pre-exposure prophylaxis), for which limited adherence has been a major barrier ${ }^{142}$.

Long-acting injectable antiretroviral drugs have the potential to address these concerns. Cabotegravir (an integrase strand transfer inhibitor related to dolutegravir) and rilpivirine (a US FDA-approved NNRTI) have both been formulated as long-acting injectables. Monthly (and perhaps even less frequent) injections are feasible and seem to offer protection; a formulation of cabotegravir given monthly has been shown to protect macaques from acquiring SIV infection after high-dose exposures ${ }^{210}$. In addition to the development of these long-acting injectable drugs, monthly insertion of vaginal rings containing antiretroviral agents is being evaluated as a means to prevent HIV acquisition in women ${ }^{152}$. 


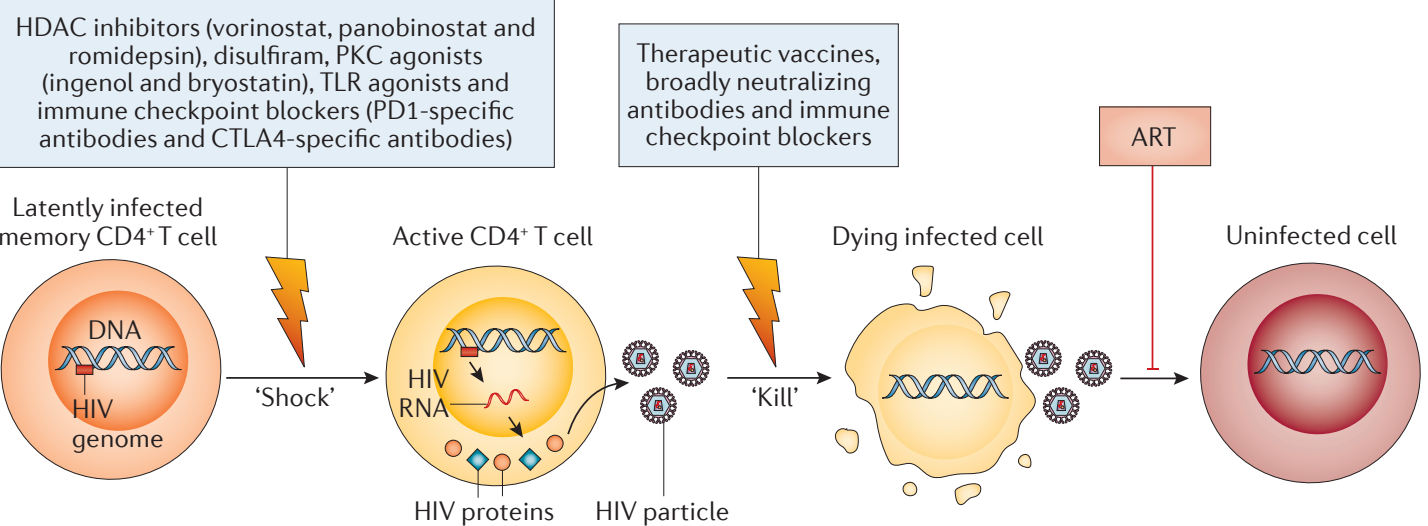

Figure $8 \mid$ Shock and kill for the cure. Integration of silenced HIV genomes into the host genome of long-lived CD4+ memory cells (latency) results in lifelong infection. Most attempts to cure HIV infection involve efforts to reverse latency, resulting in the production of viral proteins and eventually host-mediated clearance of the virus-producing cell ('shock and kill'). ART, antiretroviral therapy; CTLA4, cytotoxic T lymphocyte antigen 4; HDAC, histone deacteylase; PD1, programmed cell death protein 1; PKC, protein kinase C; TLR, Toll-like receptor.

\section{Vaccines}

Several new HIV vaccine approaches are currently under development or in early phase testing (see www.avac.org and www.iavi.org). Numerous broadly neutralizing antibodies have been identified and are being developed to target conserved regions of HIV envelope. Many of these antibodies can neutralize as much as $90 \%$ of HIV strains, and when combined, can neutralize an even higher percentage $^{211}$. These antibodies are highly protective when administered passively in animal challenge models. Plans are underway to test these antibodies as passive immunoprophylaxis ${ }^{211}$; if successful, these studies will create a target threshold of neutralizing antibody needed for protection and might be reverse-engineered to facilitate active immunization strategies.

A vaccine using a recombinant rhesus cytomegalovirus vector failed to prevent SIV acquisition in monkeys but resulted in an apparent elimination of the infection in approximately $50 \%$ of those that acquired the virus ${ }^{212,213}$. Unlike the previous approach that relies on antibodymediated protection, the mechanism of action of this vaccine seems to be solely related to a cellular immune response, without the contribution of antibody-mediated protection, pointing out that multiple approaches to development of an HIV vaccine may be successful.

\section{Combination prevention}

As more-effective biomedical prevention strategies for pre-exposure prophylaxis become available, the benefit from vaccines and other newer approaches will be more challenging and expensive to evaluate. However, combined approaches might provide synergies, such as using a combination of pre-exposure prophylaxis with an active immunization strategy. In this setting, pre-exposure prophylaxis could provide protection during the immunization phase of a vaccine regimen, before the immune response has fully matured. Other combinations might also create synergies, such as combining interventions for HIV-infected and uninfected individuals within the same population.

\section{HIV cure}

Although ART is effective, it is relatively expensive (currently about $\$ 135$ per year for a generic fixed-dose combination of efavirenz-tenofovir-lamivudine in sub-Saharan Africa), has short-term and long-term toxicity and must be delivered indefinitely. Recognizing these limitations, there is growing interest for a curative intervention ${ }^{214}$. Ideally, such an intervention would be safe, scalable and result in either eradication of the virus within a person or in durable host-mediated control of the virus (much like what happens naturally in elite controllers). The successful haematopoietic stem cell transplant from a donor whose cells lacked CCR5 and was naturally resistant to HIV infection provided the first proof that a cure is possible ${ }^{215}$; complete eradication of all virus was apparently achieved in this remarkable case ${ }^{216}$. Even in the absence of complete eradication of the virus, durable host-mediated control in the presence of a very small reservoir might be feasible, as suggested by one study of 14 individuals who received early ART in France ${ }^{217}$ (BOX 4).

As the primary barrier to a cure is the presence of a very stable population of resting memory cells harbouring quiescent integrated HIV genomes (see above), emerging efforts are aimed at reversing (or activating) the virus in these cells, enabling them to produce viral proteins that can be targeted by host immune clearance mechanisms (shock and kill; FIG. 8). Several other approaches are being pursued.

\section{Final remarks}

Advances in HIV prevention, treatment and access to services have dramatically reduced the impact of HIV and AIDS globally. These remarkable advances have reversed the trend toward decreased life expectancy throughout Africa in the 1990s; indeed, there has been an overall $8 \%$ increase in life expectancy in Africa between 2000 and 2012 (REF. 218). Applying lessons learned from HIV research of the past three decades, and striving for the development of a preventive vaccine and HIV cure, could lead to a HIV-free generation. 
1. Faria, N. R. et al. HIV epidemiology. The early spread and epidemic ignition of HIV-1 in human populations. Science 346, 56-61 (2014)

2. Keele, B. F. et al. Chimpanzee reservoirs of pandemic and nonpandemic HIV-1. Science 313, 523-526 (2006).

3. Gottlieb, M. S. et al. Pneumocystis carinii pneumonia and mucosal candidiasis in previously healthy homosexual men: evidence of a new acquired cellular immunodeficiency. N. Engl. J. Med. 305, 1425-1431 (1981).

4. Barre-Sinoussi, F. et al. Isolation of a T-lymphotropic retrovirus from a patient at risk for acquired immune deficiency syndrome (AIDS). Science 220, 868-871 (1983).

5. Gallo, R. C. et al. Isolation of human T-cell leukemia virus in acquired immune deficiency syndrome (AIDS). Science 220, 865-867 (1983)

6. UN Joint Programme on HIV/AIDS. MDG 6: 15 years, 15 lessons of hope from the AIDS response. Fact sheet. UNAIDS [online], http://www.unaids.org/sites default/files/media asset/20150714_FS_MDG6 Report en.pdf (2015)

7. GBD 2013 Mortality and Causes of Death Collaborators. Global, regional, and national age-sex specific all-cause and cause-specific mortality for 240 causes of death, 1990-2013: a systematic analysis for the Global Burden of Disease Study 2013. Lancet 385, 117-171 (2015).

8. Moir, S., Chun, T. W. \& Fauci, A. S. Pathogenic mechanisms of HIV disease. Annu. Rev. Pathol. 6 223-248 (2011)

9. Haase, A. T. Perils at mucosal front lines for HIV and SIV and their hosts. Nat. Rev. Immunol. 5, 783-792 (2005).

10. Mellors, J. W. et al. Prognosis in HIV-1 infection predicted by the quantity of virus in plasma. Science 272, 1167-1170 (1996)

11. McCune, J. M. The dynamics of $\mathrm{CD} 4+{ }^{+} \mathrm{T}$-cell depletion in HIV disease. Nature 410, 974-979 (2001).

12. Deeks, S. G. \& Walker, B. D. Human immunodeficiency virus controllers: mechanisms of durable virus control in the absence of antiretroviral therapy. Immunity 27 406-416 (2007).

13. Davey, R. T. Jr et al. HIV-1 and T cell dynamics after interruption of highly active antiretroviral therapy (HAART) in patients with a history of sustained viral suppression. Proc. Natl Acad. Sci. USA 96 15109-15114 (1999).

14. UN Joint Programme on HIV/AIDS. The Gap Report Refworld [online], http://www.refworld.org/ docid/53f1e 1604.html (2014).

With a global modelling effort, UNAIDS produce detailed estimates of trends in the pandemic that are crucial for global advocacy.

15. Beyrer, C. et al. The increase in global HIV epidemics in MSM. AIDS 27, 2665-2678 (2013).

16. UN Joint Programme on HIV/AIDS. Global Report. UNAIDS reports on the global AIDS epidemic 2013 UNAIDS [online], http://www.unaids.org/sites/default files/media asset/UNAIDS Global_Report 2013 en_1.pdf (2013).

17. Shisana, O. et al. South African National HIV Prevalence, Incidence and Behaviour Survey, 2012 (HSRC Press, 2014).

18. Gregson, S. et al. HIV decline in Zimbabwe due to reductions in risky sex? Evidence from a comprehensive epidemiological review. Int. J. Epidemiol. 39, 1311-1323 (2010).

19. Rosen, S. \& Fox, M. P. Retention in HIV care between testing and treatment in sub-Saharan Africa: a systematic review. PLoS Med. 8, e1001056 (2011).

20. McMahon, J. H., Elliott, J. H., Hong, S. Y., 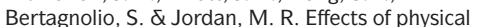 tracing on estimates of loss to follow-up, mortality and retention in low and middle income country antiretroviral therapy programs: a systematic review. PLOS ONE 8, e56047 (2013).

21. Wu, L. \& KewalRamani, V. N. Dendritic-cell interactions with HIV: infection and viral dissemination. Nat. Rev. Immunol. 6, 859-868 (2006).

22. Zeng, M. et al. Cumulative mechanisms of lymphoid tissue fibrosis and T cell depletion in HIV-1 and SIV infections. J. Clin. Invest. 121, 998-1008 (2011)

23. Estes, J. D. et al. Simian immunodeficiency virusinduced lymphatic tissue fibrosis is mediated by transforming growth factor $\beta 1$-positive regulatory $\mathrm{T}$ cells and begins in early infection. J. Infect. Dis. 195 , 551-561 (2007)
24. Sanchez, J. L. et al. Lymphoid fibrosis occurs in longterm nonprogressors and persists with antiretroviral therapy but may be reversible with curative interventions. J. Infect. Dis. 211, 1068-1075 (2015).

25. Zeng, M. et al. Lymphoid tissue damage in HIVinfection depletes naive $T$ cells and limits $T$ cell reconstitution after antiretroviral therapy. PLoS Pathog. 8, e 1002437 (2012).

26. Overbaugh, J. \& Bangham, C. R. Selection forces and constraints on retroviral sequence variation. Science 292, 1106-1109 (2001)

27. Shankarappa, R. et al. Consistent viral evolutionary changes associated with the progression of human immunodeficiency virus type 1 infection. J. Virol. 73, 10489-10502 (1999).

28. Piantadosi, A. et al. HIV-1 evolution in gag and env is highly correlated but exhibits different relationships with viral load and the immune response. AIDS 23 , 579-587 (2009)

29. Korber, B. et al. Evolutionary and immunological implications of contemporary HIV-1 variation. Br. Med. Bull. 58, 19-42 (2001).

30. Spira, A. I. et al. Cellular targets of infection and route of viral dissemination after an intravaginal inoculation of simian immunodeficiency virus into rhesus macaques. J. Exp. Med. 183, 215-225 (1996).

31. Zhang, Z. et al. Sexual transmission and propagation of SIV and HIV in resting and activated CD4 ${ }^{+}$T cells. Science 286, 1353-1357 (1999).

32. Miller, C. J. et al. Propagation and dissemination of infection after vaginal transmission of simian immunodeficiency virus. J. Virol. 79, 9217-9227 (2005)

33. Sagar, M. HIV-1 transmission biology: selection and characteristics of infecting viruses. J. Infect. Dis. 202, S289-S296 (2010)

34. Keele, B. F. et al. Identification and characterization of transmitted and early founder virus envelopes in primary HIV-1 infection. Proc. Natl Acad. Sci. USA 105, 7552-7557 (2008).

35. Connor, R. I., Sheridan, K. E., Ceradini, D., Choe, S. $\&$ Landau, N. R. Change in coreceptor use correlates with disease progression in HIV-1-infected individuals. J. Exp. Med. 185, 621-628 (1997)

36. Scarlatti, G. et al. In vivo evolution of HIV-1 co-receptor usage and sensitivity to chemokinemediated suppression. Nat. Med. 3, 1259-1265 (1997)

37. Long, E. M., Rainwater, S. M., Lavreys, L., Mandaliya, K. \& Overbaugh, J. HIV type 1 variants transmitted to women in Kenya require the CCR5 coreceptor for entry, regardless of the genetic complexity of the infecting virus. AIDS Res. Hum. Retroviruses 18, 567-576 (2002).

38. Dean, M. et al. Genetic restriction of HIV-1 infection and progression to AIDS by a deletion allele of the CKR5 structural gene. Hemophilia Growth and Development Study, Multicenter AIDS Cohort Study, Multicenter Hemophilia Cohort Study, San Francisco City Cohort, ALIVE Study. Science 273, 1856-1862 (1996).

39. Sheppard, H. W. et al. HIV-1 infection in individuals with the CCR5- $\triangle 32 / \Delta 32$ genotype: acquisition of syncytium-inducing virus at seroconversion. J. Acquir. Immune Defic. Syndr. 29, 307-313 (2002).

40. Liu, R. et al. Homozygous defect in HIV-1 coreceptor accounts for resistance of some multiply-exposed individuals to HIV-1 infection. Cell 86, 367-377 (1996)

41. Samson, M. et al. Resistance to HIV-1 infection in caucasian individuals bearing mutant alleles of the CCR-5 chemokine receptor gene. Nature 382 722-725 (1996)

42. Sagar, M. Origin of the transmitted virus in HIV infection: infected cells versus cell-free virus. J. Infect. Dis. 210, S667-S673 (2014)

43. Redd, A. D. et al. Previously transmitted HIV-1 strains are preferentially selected during subsequent sexual transmissions. J. Infect. Dis. 206, 1433-1442 (2012).

44. Derdeyn, C. A. et al. Envelope-constrained neutralization-sensitive HIV-1 after heterosexual transmission. Science 303, 2019-2022 (2004).

45. Chohan, B. et al. Selection for human immunodeficiency virus type 1 envelope glycosylation variants with shorter V1-V2 loop sequences occurs during transmission of certain genetic subtypes and may impact viral RNA levels. J. Virol. 79, 6528-6531 (2005)

46. Gnanakaran, S. et al. Recurrent signature patterns in HIV-1 B clade envelope glycoproteins associated with either early or chronic infections. PLoS Pathog. 7 e1002209 (2011).

47. Fenton-May, A. E. et al. Relative resistance of HIV-1 founder viruses to control by interferon-alpha. Retrovirology 10, 146 (2013).

48. Parrish, N. F. et al. Phenotypic properties of transmitted founder HIV-1. Proc. Natl Acad. Sci. USA 110, 6626-6633 (2013).

49. Stacey, A. R. et al. Induction of a striking systemic cytokine cascade prior to peak viremia in acute human immunodeficiency virus type 1 infection, in contrast to more modest and delayed responses in acute hepatitis $B$ and $C$ virus infections. J. Virol. 83, 3719-3733 (2009).

50. Sandler, N. G. et al. Type I interferon responses in rhesus macaques prevent SIV infection and slow disease progression. Nature 511, 601-605 (2014).

51. Kelley, C. F., Barbour, J. D. \& Hecht, F. M. The relation between symptoms, viral load, and viral load set point in primary HIV infection. J. Acquir. Immune Defic. Syndr. 45, 445-448 (2007).

52. Koup, R. A. et al. Temporal association of cellular immune responses with the initial control of viremia in primary human immunodeficiency virus type 1 syndrome. J. Virol. 68, 4650-4655 (1994).

53. Richardson, B. A. et al. Comparison of human immunodeficiency virus type 1 viral loads in Kenyan women, men, and infants during primary and early infection. J. Virol. 77, 7120-7123 (2003).

54. Lyles, R. H. et al. Natural history of human immunodeficiency virus type 1 viremia after seroconversion and proximal to AIDS in a large cohort of homosexual men. J. Infect. Dis. 181, 872-880 (2000).

55. Kimata, J. T., Kuller, L., Anderson, D. B., Dailey, P. \& Overbaugh, J. Emerging cytopathic and antigenic simian immunodeficiency virus variants influence AIDS progression. Nat. Med. 5, 535-541 (1999).

56. Hecht, F. M. et al. HIV RNA level in early infection is predicted by viral load in the transmission source. AIDS 24, 941-945 (2010)

57. Obimbo, E. M. et al. Pediatric HIV-1 in Kenya: pattern and correlates of viral load and association with mortality. J. Acquir. Immune Defic. Syndr. 51 209-215 (2009)

58. Fraser, C. et al. Virulence and pathogenesis of HIV-1 infection: an evolutionary perspective. Science 343 1243727 (2014)

59. Alizon, S. et al. Phylogenetic approach reveals that virus genotype largely determines HIV set-point viral load. PLoS Pathog. 6, e1001123 (2010)

60. Buzon, M. J. et al. HIV-1 persistence in CD4 ${ }^{+}$ $\mathrm{T}$ cells with stem cell-like properties. Nat. Med. 20 , 139-142 (2014)

61. Chomont, N. et al. HIV reservoir size and persistence are driven by T cell survival and homeostatic proliferation. Nat. Med. 15, 893-900 (2009).

62. Finzi, D. et al. Identification of a reservoir for HIV-1 in patients on highly active antiretroviral therapy. Science 278, 1295-1300 (1997).

63. Wong, J. K. et al. Recovery of replication-competent HIV despite prolonged suppression of plasma viremia. Science 278, 1291-1295 (1997).

64. Chun, T. W. et al. Quantification of latent tissue reservoirs and total body viral load in HIV-1 infection. Nature 387, 183-188 (1997)

65. Chun, T. W. et al. Early establishment of a pool of latently infected, resting $\mathrm{CD} 4^{+} \mathrm{T}$ cells during primary HIV-1 infection. Proc. Natl Acad. Sci. USA 95, 8869-8873 (1998).

66. Whitney, J. B. et al. Rapid seeding of the viral reservoi prior to SIV viraemia in rhesus monkeys. Nature $\mathbf{5 1 2}$ 74-77 (2014)

67. Buzon, M. J. et al. HIV-1 replication and immune dynamics are affected by raltegravir intensification of HAART-suppressed subjects. Nat. Med. 16, 460-465 (2010).

68. Hatano, H. et al. Increase in 2-long terminal repeat circles and decrease in D-dimer after raltegravir intensification in patients with treated HIV Infection a randomized, placebo-controlled trial. J. Infect. Dis. 208, 1436-1442 (2013).

69. Fletcher, C. V. et al. Persistent HIV-1 replication is associated with lower antiretroviral drug concentrations in lymphatic tissues. Proc. Natl Acad. Sci. USA 111, 2307-2312 (2014).

70. Fukazawa, Y. et al. B cell follicle sanctuary permits persistent productive simian immunodeficiency virus infection in elite controllers. Nat. Med. 21, 132-139 (2015). 
71. Siliciano, J. D. et al. Long-term follow-up studies confirm the stability of the latent reservoir for HIV- 1 in resting CD4+ T cells. Nat. Med. 9, 727-728 (2003). This longitudinal study demonstrates that HIV persists at low levels indefinitely even during effective combination ART. Antiretroviral drugs must, therefore, be given indefinitely to prevent viral rebound

72. Fellay, J. et al. A whole-genome association study of major determinants for host control of HIV-1. Science 317, 944-947 (2007).

73. Pereyra, F. et al. The major genetic determinants of HIV-1 control affect HLA class I peptide presentation. Science 330, 1551-1557 (2010).

74. Day, C. L. et al. PD-1 expression on HIV-specific T cells is associated with T-cell exhaustion and disease progression. Nature 443, 350-354 (2006).

75. Trautmann, L. et al. Upregulation of PD-1 expression on HIV-specific CD $8{ }^{+} \mathrm{T}$ cells leads to reversible immune dysfunction. Nat. Med. 12, 1198-1202 (2006).

76. Deng, K. et al. Broad CTL response is required to clea latent HIV-1 due to dominance of escape mutations. Nature 517, 381-385 (2015)

77. Lewis, G. K. Role of Fc-mediated antibody function in protective immunity against HIV-1. Immunology 142 46-57 (2014).

78. Wei, X. et al. Antibody neutralization and escape by HIV-1. Nature 422, 307-312 (2003).

79. West, A. P. Jr et al. Structural insights on the role of antibodies in HIV-1 vaccine and therapy. Cell 156, 633-648 (2014).

80. Sheehy, A. M., Gaddis, N. C., Choi, J. D. \& Malim, M. H. Isolation of a human gene that inhibits HIV-1 infection and is suppressed by the viral Vif protein. Nature 418, 646-650 (2002).

81. Laguette, N. et al. SAMHD1 is the dendritic- and myeloid-cell-specific HIV-1 restriction factor counteracted by Vpx. Nature 474, 654-657 (2011).

82. Neil, S. J., Zang, T. \& Bieniasz, P. D. Tetherin inhibits retrovirus release and is antagonized by HIV-1 Vpu. Nature 451, 425-430 (2008).

83. Schwartz, O., Marechal, V., Le Gall, S., Lemonnier, F. \& Heard, J. M. Endocytosis of major histocompatibility complex class I molecules is induced by the HIV-1 Nef protein. Nat. Med. 2, 338-342 (1996)

84. Redd, A. D., Quinn, T. C. \& Tobian, A. A. Frequency and implications of HIV superinfection Lancet Infect. Dis. 13, 622-628 (2013).

85. Ronen, K. et al. HIV-1 superinfection occurs less frequently than initial infection in a cohort of high-risk Kenyan women. PLoS Pathog. 9, e1003593 (2013).

86. Brenchley, J. M. et al. Microbial translocation is a cause of systemic immune activation in chronic HIV infection. Nat. Med. 12, 1365-1371 (2006)

87. Giorgi, J. V. et al. Predictive value of immunologic and virologic markers after long or short duration of HIV-1 infection. J. Acquir. Immune Defic. Syndr. 29, 346-355 (2002)

88. Deeks, S. G. et al. Immune activation set point during early HIV infection predicts subsequent CD4 T-cell changes independent of viral load. Blood 104 942-947 (2004)

89. Doitsh, G. et al. Cell death by pyroptosis drives CD4 T-cell depletion in HIV-1 infection. Nature 505 509-514 (2014)

90. Quinn, T. C. et al. Viral load and heterosexual transmission of human immunodeficiency virus type N. Engl. J. Med. 342, 921-929 (2000).

91. Baeten, J. M. et al. Genital HIV-1 RNA predicts risk of heterosexual HIV-1 transmission. Sci. Transl. Med. 3, $77 \mathrm{ra29}$ (2011)

92. Rottingen, J. A., Cameron, D. W. \& Garnett, G. P. A systematic review of the epidemiologic interactions between classic sexually transmitted diseases and HIV: how much really is known? Sex. Transm. Dis. 28 579-597 (2001).

93. Weiss, H. A., Quigley, M. A. \& Hayes, R. J. Male circumcision and risk of HIV infection in sub-Saharan Africa: a systematic review and meta-analysis. AIDS 14, 2361-2370 (2000)

94. Lemos, M. P. et al. The inner foreskin of healthy males at risk of HIV infection harbors epithelial CD4 ${ }^{+}$CCR5 cells and has features of an inflamed epidermal barrier. PLOS ONE 9, e108954 (2014).

95. Hirbod, T. et al. HIV acquisition is associated with increased antimicrobial peptides and reduced HIV neutralizing IgA in the foreskin prepuce of uncircumcised men. PLoS Pathog. 10, e1004416 (2014).

96. Dinh, M. H. et al. Visualization of HIV-1 interactions with penile and foreskin epithelia: clues for female-to-male HIV transmission. PLoS Pathog. 11 e1004729 (2015).

97. Polis, C. B. \& Curtis, K. M. Use of hormonal contraceptives and HIV acquisition in women: a systematic review of the epidemiological evidence. Lancet Infect. Dis. 13, 797-808 (2013). This is an excellent synthesis of the evidence for and against the role of hormonal contraception increasing HIV infection acquisition in women.

98. Carnegie, N. B. \& Morris, M. Size matters: concurrency and the epidemic potential of HIV in small networks. PLOS ONE 7, e43048 (2012)

99. New York State Department of Health. Quick reference guide - laboratory testing for the diagnosis of HIV infection: updated recommendations. $C D C$ [online], http://www.cdc.gov/hiv/pdf/ testingHIValgorithmQuickRef.pdf (2014)

00. Gokengin, D. et al. 2014 European guideline on HIV testing. Int. J. STD AIDS 25, 695-704 (2014).

101. Hollingsworth, T. D., Anderson, R. M. \& Fraser, C. HIV-1 transmission, by stage of infection. J. Infect. Dis. 198, 687-693 (2008)

102. Bellan, S. E., Dushoff, J., Galvani, A. P. \& Meyers, L. A. Reassessment of HIV-1 acute phase infectivity: accounting for heterogeneity and study design with simulated cohorts. PloS Med. 12, e1001801 (2015)

103. Hollingsworth, T. D., Pilcher, C. D., Hecht, F. M., Deeks, S. G. \& Fraser, C. High transmissibility during early HIV infection among men who have sex with men - San Francisco, California. J. Infect. Dis. 211, 1757-1760 (2015).

104. Marks, G., Crepaz, N. \& Janssen, R. S. Estimating sexual transmission of HIV from persons aware and unaware that they are infected with the virus in the USA. AIDS 20,1447-1450 (2006).

105. Pilcher, C. D. et al. Performance of rapid point-of-care and laboratory tests for acute and established HIV infection in San Francisco. PLoS ONE 8, e80629 (2013)

106. Amor, A. et al. Seroreversion of HIV antibodies in patients with prolonged suppression of viraemia under HAART. AIDS 20, 1460-1462 (2006).

107. Moyer, V. A. \& U.S. Preventative Services Task Force. Screening for HIV: U.S. Preventive Services Task Force Recommended Statement. Ann. Intern. Med. 159 51-60 (2013)

108. World Health Organization. Consolidated Guidelines on HIV Prevention, Diagnosis, Treatment and Care for Key Populations (WHO Press, 2014).

109. Centers for Disease Control and Prevention. Revised recommendations for HIV testing of adults, adolescents, and pregnant women in health-care settings. MMWR 55, 1-17 (2006)

110. Zetola, N. M. et al. Simplifying consent for HIV testing is associated with an increase in HIV testing and case detection in highest risk groups, San Francisco January 2003-June 2007. PLOS ONE 3, e2591 (2008).

111. Haukoos, J. S. et al. Routine opt-out rapid HIV screening and detection of HIV infection in emergency department patients. JAMA 304, 284-292 (2010).

112. Baisley, K. et al. Uptake of voluntary counselling and testing among young people participating in an HIV prevention trial: comparison of opt-out and opt-in strategies. PLOS ONE 7, e42108 (2012).

113. Weller, S. \& Davis, K. Condom effectiveness in reducing heterosexual HIV transmission. Cochrane Database Syst. Rev. 1, CD003255 (2002).

114. Smith, D. K., Herbst, J. H., Zhang, X. \& Rose, C. E. Condom effectiveness for HIV prevention by consistency of use among men who have sex with men in the United States. J. Acquir. Immune Defic. Syndr. 68, 337-344 (2015).

115. Remis, R. S., Alary, M., Liu, J., Kaul, R. \& Palmer, R. W. HIV transmission among men who have sex with men due to condom failure. PLOS ONE 9, e107540 (2014).

116. Aspinall, E. J. et al. Are needle and syringe programmes associated with a reduction in HIV transmission among people who inject drugs: a systematic review and meta-analysis. Int. J. Epidemiol. 43, 235-248 (2014).

117. Nduati, R., Mbori-Ngacha, D., John, G., Richardson, B. \& Kreiss, J. Breastfeeding in women with HIV. JAMA 284, 956-957 (2000)

118. de Vincenzi, I. Triple antiretroviral compared with zidovudine and single-dose nevirapine prophylaxis during pregnancy and breastfeeding for prevention of mother-to-child transmission of HIV-1 (Kesho Bora study): a randomised controlled trial. Lancet Infect. Dis. 11, 171-180 (2011)

119. Mofenson, L. M. Prevention in neglected subpopulations: prevention of mother-to-child transmission of HIV infection. Clin. Infect. Dis. $\mathbf{5 0}$ S130-S148 (2010)

120. World Health Organization. Consolidated Guideline on the Use of Antiretroviral Drugs for Treating and Preventing HIV Infection: Recommendations for a Public Health Approach (WHO Press, 2013). WHO guidelines for a public health approach to ART provision have been crucial in guiding the rollout of ART. The most recent guidelines expanded the eligibility criteria for ART initiation substantially.

121. Auvert, B. et al. Randomized, controlled intervention trial of male circumcision for reduction of HIV infection risk: the ANRS 1265 Trial. PLoS Med. 2, e298 (2005).

122. Bailey, R. C. et al. Male circumcision for HIV prevention in young men in Kisumu, Kenya: a randomised controlled trial. Lancet 369, 643-656 (2007).

123. Gray, R. H. et al. Male circumcision for HIV prevention in men in Rakai, Uganda: a randomised trial. Lancet 369, 657-666 (2007).

124. Gray, R. H. et al. The effectiveness of male circumcision for HIV prevention and effects on risk behaviors in a posttrial follow-up study. Aids 26, 609-615 (2012).

125. Wawer, M. J. et al. Circumcision in HIV-infected men and its effect on HIV transmission to female partners in Rakai, Uganda: a randomised controlled trial. Lancet 374, 229-237 (2009).

126. Gray, R. H. et al. Effects of genital ulcer disease and herpes simplex virus type 2 on the efficacy of male circumcision for HIV prevention: analyses from the Rakai trials. PLoS Med. 6, e1000187 (2009).

127. UNAIDS/WHO/SACEMA Expert Group on Modelling the Impact and Cost of Male Circumcision for HIV Prevention. Male circumcision for HIV prevention in high HIV prevalence settings: what can mathematical modelling contribute to informed decision making? PLoS Med. 6, e1000109 (2009).

128. Goodreau, S. M. et al. Can male circumcision have an impact on the HIV epidemic in men who have sex with men? PLOS ONE 9, e102960 (2014).

129. Cohen, M. S. et al. Prevention of HIV-1 infection with early antiretroviral therapy. N. Engl. J. Med. 365, 493-505 (2011)

This paper presents a randomized controlled trial of early versus standard initiation of ART to prevent transmission of HIV to an uninfected sexual partner.

130. Rodger, A. et al. Abtract 153LB: HIV transmission risk through condomless sex if $\mathrm{HIV}^{+}$partner on suppressive ART: PARTNER study. NAPWHA [online], http://napwha.org.au/sites/default/files/CROI\% 20Abstract\%20153LB_0.pdf (2014).

131. Grulich, A. E. et al. HIV transmission in male serodiscordant couples in Australia, Thailand and Brazil. CROI [online], http://www.croiconference.org sessions/hiv-transmission-male-serodiscordantcouples-australia-thailand-and-brazil (2015).

132. Mujugira, A. et al. HIV-1 transmission risk persists during the first 6 months of antiretroviral therapy. CROI [online], http://www.croiconference.org/sessions/ hiv-1-transmission-risk-persists-during-first-6-monthsantiretroviral-therapy (2015)

133. Gardner, L. I. et al. Time above 1500 copies $/ \mathrm{ml}$ a viral-load measure for assessing transmission risk of HIV-positive patients in care. AIDS 29, 947-954 (2015).

134. Tsai, C. C. et al. Prevention of SIV infection in macaques by $(R)$-9-(2- phosphonylmethoxypropyl) adenine. Science 270, 1197-1199 (1995).

135. Cardo, D. M. et al. A case-control study of HIV seroconversion in health care workers after percutaneous exposure. N. Engl. J. Med. 337, 1485-1490 (1997).

136. Kuhar, D. T. et al. Updated US Public Health Service guidelines for the management of occupational exposures to human immunodeficiency virus and recommendations for postexposure prophylaxis. Infect. Control Hosp. Epidemiol. 34, 875-892 (2013). These are the most recent guidelines for post-exposure prophylaxis in the United States.

137. Joyce, P. M., Kuhar, D. \& Brooks, J. T. Occupationally acquired HIV infection by healthcare personnel United States, 1985-2013 (poster). CROI [online], http://www.croiconference.org/sites/default/files posters-2015/1027.pdf (2015).

138. McCormack, S. \& Dunn, D. Pragmatic open-label randomised trial of preexposure prophylaxis: the PROUD study. CROI [online], http://www. croiconference.org/sessions/pragmatic-open-labelrandomised-trial-preexposure-prophylaxis-proud-study (2015). 
139. Baeten, J. M. et al. Antiretroviral prophylaxis for HIV prevention in heterosexual men and women. N. Engl. J. Med. 367, 399-410 (2012)

140. Grant, R. M. et al. Preexposure chemoprophylaxis for HIV prevention in men who have sex with men. N. Engl. J. Med. 363, 2587-2599 (2010).

141. Choopanya, K. et al. Antiretroviral prophylaxis for HIV infection in injecting drug users in Bangkok, Thailand (the Bangkok Tenofovir Study): a randomised, doubleblind, placebo-controlled phase 3 trial. Lancet 381, 2083-2090 (2013).

142. Marrazzo, J. M. et al. Tenofovir-based preexposure prophylaxis for HIV infection among African women. N. Engl. J. Med. 372, 509-518 (2015).

143. Van Damme, L. et al. Preexposure prophylaxis for HIV infection among African women. N. Engl. J. Med. 367 411-422 (2012)

144. Anderson, P. L. et al. Emtricitabine-tenofovir concentrations and pre-exposure prophylaxis efficacy in men who have sex with men. Sci. Transl. Med. 4 , 151 ra125 (2012).

This paper explores the potential 'forgiveness' of less than daily dosing of TDF/FTC pre-exposure prophylaxis.

145. Kashuba, A. D. et al. Genital tenofovir concentrations correlate with protection against HIV infection in the CAPRISA 004 trial. J. Acquir. Immine Defic. Syndr. 69, 264-269 (2015)

146. Molina, J. M. et al. On demand PrEP with oral TDF-FTC in MSM: results of the ANRS Ipergay trial. CROI [online], http://www.croiconference.org/sessions/demand-preporal-tdf-ftc-msm-results-anrs-ipergay-trial (2015).

147. World Health Organization. Guidance on Oral PreExposure Prophylaxis (PrEP) for Serodiscordant Couples, Men and Transgender Women Who Have Sex with Men at High Risk of HIV (WHO Press, 2012).

148. Centers for Disease Control and Prevention. Interim guidance: preexposure prophylaxis for the prevention of HIV infection in men who have sex with men MMWR 60, 65-68 (2011).

These are the most recent pre-exposure prophylaxis guidelines from the Centers for Disease Control and Prevention.

149. Smith, D. et al. Update to interim guidance for preexposure prophylaxis (PrEP) for the prevention of HIV infection: PrEP for injecting drug users. MMWR 62, 463-465 (2013)

150. National Institute of Allergy and Infectious Diseases. Evaluating the safety, tolerability, and pharmacokinetics of an investigational, injectable HIV medicine (GSK1265744) in HIV-uninfected adults. ClinicalTrials.gov [online], http://clinicaltrials.gov/ct2/ show/NCT02178800 (2014)

151. International Partnership for Microbicides, Inc. Safety and efficacy trial of a dapivirine vaginal matrix ring in healthy HIV-negative women. ClinicalTrials.gov [online], http://clinicaltrials.gov/ct2/show/ NCT01539226 (2012).

152. International Partnership for Microbicides, Inc. Phase 3 safety and effectiveness trial of dapivirine vaginal ring for prevention of HIV-1 in women (ASPIRE). ClinicalTrials.gov [online], http://clinicaltrials.gov/ct2/ show/NCT01617096 (2012).

153. Tellalian, D., Maznavi, K., Bredeek, U. F. \& Hardy, W. D. Pre-exposure prophylaxis (PrEP) for HIV infection: results of a survey of HIV healthcare providers evaluating their knowledge, attitudes, and prescribing practices. AIDS Patient Care STDS 27 , 553-559 (2013)

154. Barouch, D. H. \& Picker, L. J. Novel vaccine vectors for HIV-1. Nat. Rev. Microbiol. 12, 765-771 (2014).

155. Haynes, B. F. \& Bradley, T. Broadly neutralizing antibodies and the development of vaccines. JAMA 313, 2419-2420 (2015)

This is an excellent and clear summary of the search for correlates of protection from a successful HIV vaccine trial.

156. Hansen, S. G. et al. Immune clearance of highly pathogenic SIV infection. Nature 502, 100-104 (2013).

157. Rerks-Ngarm, S. et al. Vaccination with ALVAC and AIDSVAX to prevent HIV- 1 infection in Thailand. N. Engl. J. Med. 361, 2209-2220 (2009)

158. Haynes, B. F. et al. Immune-correlates analysis of an HIV-1 vaccine efficacy trial. N. Engl. J. Med. 366, 1275-1286 (2012).

159. Hallett, T. B. et al. Understanding the impact of male circumcision interventions on the spread of HIV in southern Africa. PLoS ONE 3, e2212 (2008). This paper demonstrates the potential for synergies from combining different prevention modalities.
160. HIV Prevention Trials Network. Population effects of antiretroviral therapy to reduce HIV Transmission (PopART). ClinicalTrials.gov [online], http:// clinicaltrials.gov/ct2/show/NCT01900977 (2013).

161. Mallal, S. et al. HLA-B*5701 screening for hypersensitivity to abacavir. N. Engl. J. Med. 358 568-579 (2008)

162. Sabin, C. A. et al. Use of nucleoside reverse transcriptase inhibitors and risk of myocardial infarction in HIV-infected patients enrolled in the D:A:D study: a multi-cohort collaboration. Lancet 371 1417-1426 (2008)

163. Taiwo, B. et al. Efficacy of a nucleoside-sparing regimen of darunavir/ritonavir plus raltegravir in treatment-naive HIV-1-infected patients (ACTC A5262). AIDS 25, 2113-2122 (2011).

164. Cahn, P. et al. Dual therapy with lopinavir and ritonavir plus lamivudine versus triple therapy with lopinavir and ritonavir plus two nucleoside reverse transcriptase inhibitors in antiretroviral-therapy-naive adults with HIV-1 infection: 48 week results of the randomised, open label, non-inferiority GARDEL trial. Lancet Infect. Dis. 14, 572-580 (2014).

165. Clotet, B. et al. Once-daily dolutegravir versus darunavir plus ritonavir in antiretroviral-naive adults with HIV-1 infection (FLAMINGO): 48 week results from the randomised open-label phase $3 \mathrm{~b}$ study. Lancet 383, 2222-2231 (2014).

166. Walmsley, S. L. et al. Dolutegravir plus abacavirlamivudine for the treatment of HIV-1 infection. N. Engl. J. Med. 369, 1807-1818 (2013).

167. Raffi, F. et al. Once-daily dolutegravir versus twicedaily raltegravir in antiretroviral-naive adults with HIV-1 infection (SPRING-2 study): 96 week results from a randomised, double-blind, non-inferiority trial. Lancet Infect. Dis. 13, 927-935 (2013).

168. Lennox, J. L. et al. Efficacy and tolerability of 3 nonnucleoside reverse transcriptase inhibitor-sparing antiretroviral regimens for treatment-naive volunteers infected with HIV-1: a randomized, controlled equivalence trial. Ann. Intern. Med. 161, 461-47 (2014).

169. Rockstroh, J. K. et al. Long-term treatment with raltegravir or efavirenz combined with tenofovir emtricitabine for treatment-naive human immunodeficiency virus-1-infected patients: 156-week results from STARTMRK. Clin. Infect. Dis. 53, 807-816 (2011).

170. DHHS Panel on Antiretroviral Guidelines for Adults and Adolescents. Guidelines for the use of antiretroviral agents in HIV-1-infected adults and adolescents. AIDSinfo [online], https://aidsinfo.nih.gov/contentfiles/ Ivguidelines/adultandadolescentgl.pdf (2015).

171. Mollan, K. R. et al. Association between efavirenz as initial therapy for HIV-1 infection and increased risk for suicidal ideation or attempted or completed suicide: an analysis of trial data. Ann. Intern. Med. 161, 1-10 (2014).

172. Puls, R. et al. Efficacy of $400 \mathrm{mg}$ efavirenz versus standard $600 \mathrm{mg}$ dose in HIV-infected, antiretroviralnaive adults (ENCORE1): a randomised, double-blind, placebo-controlled, non-inferiority trial. Lancet 383 , 1474-1482 (2014).

173. Cohen, C. et al. Week 48 results from a randomized clinical trial of rilpivirine/emtricitabine/tenofovir disoproxil fumarate versus efavirenz/emtricitabine/ tenofovir disoproxil fumarate in treatment-naive HIV-1-infected adults. AIDS 28, 989-997 (2014).

174. Günthard, H. F. et al. Antiretroviral treatment of adult HIV infection: 2014 recommendations of the International Antiviral Society-USA Panel. JAMA 312 , 410-425 (2014).

175. Acosta, E. P. et al. Novel method to assess antiretroviral target trough concentrations using in vitro susceptibility data. Antimicrob. Agents Chemother. 56, 5938-5945 (2012)

176. Friis-Møller, N. et al. Class of antiretroviral drugs and the risk of myocardial infarction. N. Engl. J. Med. 356 , 1723-1735 (2007)

177. Severe, P. et al. Early versus standard antiretroviral therapy for HIV-infected adults in Haiti. N. Engl. J. Med. 363, 257-265 (2010).

178. Grinsztejn, B. et al. Effects of early versus delayed initiation of antiretroviral treatment on clinical outcomes of HIV- 1 infection: results from the phase 3 HPTN 052 randomised controlled trial. Lancet Infect. Dis. 14, 281-290 (2014)

179. Emery, S. et al. Major clinical outcomes in antiretroviral therapy (ART)-naive participants and in those not receiving ART at baseline in the SMART study. J. Infect. Dis. 197, 1133-1144 (2008).
180. Williams, I. et al. British HIV Association guidelines for the treatment of HIV-1-positive adults with antiretroviral therapy 2012. HIV Med. 13, S1-S85 (2012).

181. The TEMPRANO ANRS 12136 Study Group. A trial of early antiretrovirals and isoniazid preventive therapy in Africa. N. Engl. J. Med. 373, 808-822 (2015).

182. The INSIGHT START Study Group. Initiation of antiretroviral therapy in early asymptomatic HIV infection. N. Engl. J. Med. 373, 795-807 (2015)

183. Hatano, H. et al. Prospective antiretroviral treatment of asymptomatic, HIV- 1 infected controllers. PLoS Pathog. 9, e1003691 (2013).

184. Paredes, R. et al. Pre-existing minority drug-resistant HIV-1 variants, adherence, and risk of antiretroviral treatment failure. J. Infect. Dis. 201, 662-671 (2010).

185. Deeks, S. G. et al. Virologic and immunologic consequences of discontinuing combination antiretroviral-drug therapy in HIV-infected patients with detectable viremia. N. Engl. J. Med. 344 472-480 (2001)

186. Bangsberg, D. R. et al. Adherence-resistance relationships for protease and non-nucleoside reverse transcriptase inhibitors explained by virological fitness. AIDS 20, 223-231 (2006).

187. Little, S. J. et al. Antiretroviral-drug resistance among patients recently infected with HIV. N. Engl. J. Med. 347, 385-394 (2002).

188. Vercauteren, J. et al. Transmission of drug-resistant HIV-1 is stabilizing in Europe. J. Infect. Dis. 200. 1503-1508 (2009).

189. Rhee, S. Y. et al. Geographic and temporal trends in the molecular epidemiology and genetic mechanisms of transmitted HIV-1 drug resistance: an individualpatient- and sequence-level meta-analysis. PLoS Med. 12, e1001810 (2015).

190. Pham, Q. D., Wilson, D. P., Law, M. G., Kelleher, A. D. ¿ Zhang, L. Global burden of transmitted HIV drug resistance and HIV-exposure categories: a systematic review and meta-analysis. AIDS 28, 2751-2762 (2014).

191. Miners, A. et al. Health-related quality-of-life of people with HIV in the era of combination antiretroviral treatment: a cross-sectional comparison with the general population. Lancet HIV 1, e32-e40 (2014).

192. Phillips, A. N., Neaton, J. \& Lundgren, J. D. The role of HIV in serious diseases other than AIDS. AIDS 22, 2409-2418 (2008)

193. Deeks, S. G., Lewin, S. R. \& Havlir, D. V. The end of AIDS: HIV infection as a chronic disease. Lancet 382 1525-1533 (2013)

194. Freiberg, M. S. et al. HIV infection and the risk of acute myocardial infarction. JAMA Intern. Med. 173. 614-622 (2013)

195. Kuller, L. H. et al. Inflammatory and coagulation biomarkers and mortality in patients with HIV infection. PLoS Med. 5, e203 (2008).

This retrospective analysis of a randomized clinical trial provides the first definitive evidence that HIV-mediated inflammation predicted development of non-AIDS morbidity and mortality that is independent of other factors.

196. Worm, S. W. et al. Risk of myocardial infarction in patients with HIV infection exposed to specific individual antiretroviral drugs from the 3 major drug classes: the data collection on adverse events of antiHIV drugs (D:A:D) study. J. Infect. Dis. 201, 318-330 (2010).

197. Ryom, L. et al. Association between antiretroviral exposure and renal impairment among HIV-positive persons with normal baseline renal function: the D:A:D study. J. Infect. Dis. 207, 1359-1369 (2013).

198. Deeks, S. G., Tracy, R. \& Douek, D. C. Systemic effects of inflammation on health during chronic HIV infection. Immunity 39, 633-645 (2013).

199. Brothers, T. D. et al. Frailty in people aging with human immunodeficiency virus (HIV) infection. J. Infect. Dis. 210, 1170-1179 (2014).

200. Althoff, K. N. et al. Age, comorbidities, and AIDS predict a frailty phenotype in men who have sex with men. J. Gerontol. A Biol. Sci. Med. Sci. 69, 189-198 (2014).

201. Rosen, S., Fox, M. P \& Gill, C. J. Patient retention in antiretroviral therapy programs in sub-Saharan Africa: a systematic review. PLoS Med. 4, e298 (2007).

202. Fox, M. P. \& Rosen, S. Patient retention in antiretroviral therapy programs up to three years on treatment in sub-Saharan Africa, 2007-2009: systematic review. Trop. Med. Int. Health 15, 1-16 (2010). 
203. Fox, M. P. \& Rosen, S. Retention of adult patients on antiretroviral therapy in low-and middle-income countries: systematic review and meta-analysis 2008-2013. J. Acquir. Immune Defic. Syndr. 69, 98-108 (2015).

204. Bradley, H. et al. Vital signs: HIV diagnosis, care, and treatment among persons living with HIV - United States, 2011.MMWR 63, 1113-1117 (2014).

205. University of California, San Francisco. Sustainable East Africa research in community health (SEARCH) ClinicalTrials.gov [online], http://clinicaltrials. gov/ct2/ show/NCT01864603 (2013).

206. Centers for Disease Control and Prevention. Botswana Combination Prevention Project (BCPP). ClinicalTrials.gov [online], http://clinicaltrials.gov/ct2 show/NCT01965470 (2013).

207. Inserm-ANRS. Impact of immediate versus South African recommendations guided ART initiation on HIV incidence (TasP). ClinicalTrials.gov [online], http:// clinicaltrials.gov/ct2/show/NCT01509508 (2012).

208. Phillips, A. N. et al. Potential impact on HIV incidence of higher HIV testing rates and earlier antiretroviral therapy initiation in MSM. AIDS 29, 1855-1862 (2015).

209. Thompson, M. A et al Guidelines for improving entry into and retention in care and antiretrovira adherence for persons with HIV: evidence-based recommendations from an International Association of Physicians in AIDS Care panel. Ann. Intern. Med. 156 , 817-833 (2012).

210. Andrews, C. D. et al. A long-acting integrase inhibitor protects female macaques from repeated high-dose intravaginal SHIV challenge. Sci. Transl. Med. 7 , 270ra274 (2015).

211. Burton, D. R. \& Mascola, J. R. Antibody responses to envelope glycoproteins in HIV-1 infection. Nat. Immunol. 16, 571-576 (2015).

212. Picker, L. J., Hansen, S. G. \& Lifson, J. D. New paradigms for HIV/AIDS vaccine development. Annu. Rev. Med. 63, 95-111 (2012). This paper outlines the challenges and potential strategies for developing an effective HIV vaccine.

213. Hansen, S. G. et al. Profound early control of highly pathogenic SIV by an effector memory T-cell vaccine. Nature 473, 523-527 (2011).

This elegant study demonstrated that a vaccine could induce potent SIV-specific effector CD8 ${ }^{+}$ $T$ cells and that these cells can eradicate established retroviral infection.

214. Fauci, A. S., Marston, H. D. \& Folkers, G. K. An HIV cure: feasibility, discovery, and implementation. JAMA 312, 335-336 (2014).

215. Hutter, G. et al. Long-term control of HIV by CCR5 delta32/delta32 stem-cell transplantation. N. Engl. J. Med. 360, 692-698 (2009).

This provocative case report demonstrated that HIV infection can be cured with a haematopoietic stem cell transplant and has inspired a robust international effort to develop a curative intervention.

216. Yukl, S. A. et al. Challenges in detecting HIV persistence during potentially curative interventions: a study of the Berlin patient. PLoS Pathog. 9 e1003347 (2013).

217. Sáez-Ciriōn, A et al. Post-treatment HIV-1 controllers with a long-term virological remission after the interruption of early initiated antiretroviral therapy ANRS VISCONTI study. PLoS Pathog. 9, e1003211 (2013).

218. UN Joint Programme on HIV/AIDS. Global report: UNAIDS report on the global AIDS epidemic 2013 UNAIDS [online], http://www.unaids.org/sites/default/ files/en/media/unaids/contentassets/documents/ epidemiology/2013/gr2013/UNAIDS Global Report 2013 en.pdf (2013).

219. Jewkes, R. K Dunkle K Nduna, M. \& Shai, N. Intimate partner violence, relationship power inequity, and incidence of HIV infection in young women in South Africa: a cohort study. Lancet 376, 41-48 (2010).

220. Centers for Disease Control and Prevention. Statistics Center - HIV/AIDS. CDC [online], http://www.cdc.gov/ hiv/statistics/index.html (2015)
221. Gandhi, M. et al. Does patient sex affect human immunodeficiency virus levels? Clin. Infect. Dis. 35 313-322 (2002)

222. Chang, J. J. et al. Higher expression of several interferon-stimulated genes in HIV-1-infected females after adjusting for the level of viral replication. J. Infect. Dis. 208, 830-838 (2013).

223. Triant, V. A., Lee, H., Hadigan, C. \& Grinspoon, S. K. Increased acute myocardial infarction rates and cardiovascular risk factors among patients with HIV disease. J. Clin. Endocrinol Metab 92, 2506-2512 (2007).

224. Soon, G. G. et al. Meta-analysis of gender differences in efficacy outcomes for HIV-positive subjects in randomized controlled clinical trials of antiretroviral therapy. AIDS Patient Care STDS 26, 444-453 (2012).

225. Currier, J. et al. Sex-based outcomes of darunavirritonavir therapy: a single-group trial. Ann. Intern. Med. 153, 349-357 (2010)

226. Loutfy, M. R. et al. Caring for women living with HIV gaps in the evidence. J. Int. AIDS Soc. 16, 18509 (2013).

227. Panel on Antiretroviral Therapy and Medical Management of HIV-Infected Children. Guidelines for the use of antiretroviral agents in pediatric HIV infection. AIDSinfo [online], http:// aidsinfo.nih.gov/contentfiles/lvguidelines/ pediatricguidelines.pdf (2015)

228. Marinda, E et al. Child mortality according to maternal and infant HIV status in Zimbabwe. Pediatr. Infect. Dis. J. 26, 519-526 (2007).

229. Violari, A. et al. Early antiretroviral therapy and mortality among HIV-infected infants. N. Engl. J. Med. 359, 2233-2244 (2008).

230. Puthanakit, T. et al. Early versus deferred antiretroviral therapy for children older than 1 year infected with HIV (PREDICT): a multicentre, randomised, open-label trial. Lancet Infect. Dis. 12 , 933-941 (2012).

231. Hazra, R., Siberry, G. K. \& Mofenson, L. M. Growing up with HIV: children, adolescents, and young adults with perinatally acquired HIV infection. Annu. Rev. Med. 61, 169-185 (2010)

232. Ranasinghe, S. et al. Association of HLA-DRB 1-restricted CD4+ T cell responses with HIV immune control. Nat. Med. 19, 930-933 (2013).

233. Migueles, S. A. et al. Lytic granule loading of CD8 $T$ cells is required for HIV-infected cell elimination associated with immune control. Immunity 29 , 1009-1021 (2008)

234. Ferre, A. L. et al. Mucosal immune responses to HIV-1 in elite controllers: a potential correlate of immune control. Blood 113, 3978-3989 (2009).

235. Lelic, A. et al. The polyfunctionality of human memory $\mathrm{CD} 8{ }^{+} \mathrm{T}$ cells elicited by acute and chronic virus infections is not influenced by age. PLoS Pathog. 8 e1003076 (2012)

236. Martin, M. P. et al. Innate partnership of HLA-B and KIR3DL 1 subtypes against HIV-1. Nat. Genet. 39, 733-740 (2007).

237. Emu, B. et al. HLA class I-restricted T-cell responses may contribute to the control of human immunodeficiency virus infection, but such response are not always necessary for long-term virus control. J. Virol 82, 5398-5407 (2008)

238. Miura, T. et al. HLA-associated alterations in replication capacity of chimeric NL4-3 viruses carrying gag-protease from elite controllers of human immunodeficiency virus type 1 . J. Virol. 83, 140-149 (2009).

239. Chen, H. et al. CD4 ${ }^{+}$T cells from elite controllers resist HIV-1 infection by selective upregulation of $\mathrm{p} 21$ J. Clin. Invest. 121, 1549-1560 (2011).

240. Abdel-Mohsen, M. et al. Expression profile of host restriction factors in HIV-1 elite controllers. Retrovirology 10, 106 (2013)

241. Mocroft, A. et al. Normalisation of CD4 counts in patients with HIV-1 infection and maximum virological suppression who are taking combination antiretroviral therapy: an observational cohort study. Lancet 370 407-413 (2007).
242. Baker J V et al. CD4+ count and risk of non-AIDS diseases following initial treatment for HIV infection. AIDS 22, 841-848 (2008)

243. Lichtenstein, K. A. et al. Low CD4 ${ }^{+} \mathrm{T}$ cell count is a risk factor for cardiovascular disease events in the HIV outpatient study. Clin. Infect. Dis. 51, 435-447 (2010).

244. Serrano-Villar, S. et al. HIV-infected individuals with low CD4/CD8 ratio despite effective antiretroviral therapy exhibit altered $\mathrm{T}$ cell subsets, heightened $\mathrm{CD}^{+}{ }^{+} \mathrm{T}$ cell activation, and increased risk of non-AIDS morbidity and mortality. PLoS Pathog. 10, e 1004078 (2014).

245. Hunt, P. W. et al. Gut epithelial barrier dysfunction and innate immune activation predict mortality in treated HIV infection. J. Infect. Dis. 210, 1228-1238 (2014).

246. Tenorio, A. R. et al. Soluble markers of inflammation and coagulation, but not T-cell activation, are predictors of non-AIDS-defining morbid events during suppressive antiretroviral treatment. J. Infect. Dis. 210, 1248-1259 (2014)

247. Kelley, C. F. et al. Incomplete peripheral CD4+ cell count restoration in HIV-infected patients receiving long-term antiretroviral treatment. Clin. Infect. Dis. 48, 787-794 (2009).

248. Okulicz, J. F. et al. Influence of the timing of antiretroviral therapy on the potential for normalization of immune status in human immunodeficiency virus 1 -infected individuals. JAMA Intern. Med. 175, 88-99 (2015).

249. Schneider, E. et al. Revised surveillance case definitions for HIV infection among adults, adolescents, and children aged $<18$ months and for HIV infection and AIDS among children aged 18 months to $<13$ years - United States, 2008 MMWR 57, 1-12 (2008)

250. Gulick, R. M. et al. Treatment with indinavir, zidovudine, and lamivudine in adults with human immunodeficiency virus infection and prior antiretroviral therapy. N. Engl. J. Med. 337, 734-739 (1997).

251. Engelman, A. \& Cherepanov, P. The structural biology of HIV-1: mechanistic and therapeutic insights. Nat. Rev. Microbiol. 10, 279-290 (2012).

252. Brenchley, J. M., Price, D. A. \& Douek, D. C. HIV disease: fallout from a mucosal catastrophe? Nat. Immunol. 7, 235-239 (2006).

253. Bonyhadi, M. L. et al. HIV induces thymus depletion in vivo. Nature 363, 728-732 (1993).

254. Favre D. et al. Tryptophan catabolism by indoleamine 2,3-dioxygenase 1 alters the balance of $\mathrm{T}_{\mathrm{H}} 17$ to regulatory T cells in HIV disease. Sci. Transl. Med. 2 , $32 \mathrm{ra36}(2010)$

255. Sauce, D. et al. HIV disease progression despite suppression of viral replication is associated with exhaustion of lymphopoiesis. Blood 117, 5142-5151 (2011).

256. Patel, P. et al. Estimating per-act HIV transmission risk: a systematic review. AIDS 28, 1509-1519 (2014).

\section{Acknowledgements}

The authors thank E. Abrams, J. Gallant, M. Gandhi, E. Geng, T. Ruel and S. Pillai for advice.

\section{Author contributions}

Introduction (S.G.D.); Epidemiology (S.G.D., A.P. and S.B.); Mechanisms/pathophysiology (S.G.D., J.O. and S.B.); Diagnosis, screening and prevention (S.G.D. J.O. and S.B.): Management (S.G.D. and A.P.); Quality of life (S.G.D. and A.P.); Outlook (S.G.D., J.O., A.P. and S.B.); overview of the Primer (S.G.D).

\section{Competing interests}

S.G.D. has consulted for Bristol-Myers Squibb, GlaxoSmithKline, Novartis and Janssen, and has received research support from Gilead and Merck. A.P. has attended various advisory boards, has received speaker fees for meetings in the past 4 years for Gilead Sciences and has received research support from GlaxoSmithKline. J.O. and S.B. declare no competing interests. 